\title{
Experimental analysis and preliminary assessment of an integrated thermochemical process for production of low-molecular weight biofuels from municipal solid waste (MSW)
}

\author{
Massimiliano Materazzi ${ }^{1}$, Andrew Holt ${ }^{2}$ \\ ${ }^{1}$ Department of Chemical Engineering, University College London, London (UK) \\ 2 Catal International Ltd, Sheffield, (UK)
}

\begin{abstract}
This work explores the use of advanced thermal technologies for the conversion of refuse derived fuel prepared from MSW into clean syngas suitable for catalytic transformation into light hydrocarbon products. In particular, the possibilities for the specific production of C1-C4 hydrocarbons utilising a good quality syngas produced by two-stage plasma assisted gasification method are investigated. A number of catalytic tests were prepared with modified chemistry to evaluate the preliminary component activities on real waste-derived syngas. C1-C4 paraffines formed in all cases as a main products, with different product distribution for different conditions examined (up to 95\% bioSNG on hydrocarbon product for supported nickel, 40\% bioLPG for Cu-Zn/ZSM-5 catalysts mix). $\mathrm{CO}_{2}$ was the main byproduct with outlet concentrations ranging from 10 to $50 \%$ in volume. When increasing $\mathrm{H}_{2}: \mathrm{CO}$ in the syngas by external addition of hydrogen, CO conversion increases, as well as paraffin selectivity and hydrocarbons yield. Projections on a $65 \mathrm{MW}$ thermal input bioSNG plant show that if $40 \mathrm{MW}$ of electrical output from renewable sources are used to power a PEM stack during high power availability, the production of bioSNG could be increased by more than 33\%, with a simultaneous reduction in $\mathrm{CO}_{2}$ emissions of more than $43 \%$.
\end{abstract}

Keywords: Waste gasification; biofuel; LMW hydrocarbons; thermochemical process; Waste-to-Gas

$\begin{array}{ll}\text { Abbreviations: } & \\ \text { LMW } & \text { Low molecular weight } \\ \text { GHG } & \text { Greenhouse gas } \\ \text { LPG } & \text { Liquefied petroleum gas } \\ \text { HDO } & \text { Hydrodeoxygenation } \\ \text { FAME } & \text { Fatty acid methyl esters } \\ \text { HVO } & \text { Hydrotreated vegetable oil } \\ \text { HEFA } & \text { Hydrotreated esters and fatty acids } \\ \text { SNG } & \text { Synthetic Natural Gas } \\ \text { FT } & \text { Fischer Tropsch } \\ \text { CtL } & \text { Coal to Liquid } \\ \text { GtL } & \text { Gas to Liquid } \\ \text { PtL } & \text { Power-to-Liquids } \\ \text { BtL } & \text { Biomass-to-Liquids } \\ \text { PtG } & \text { Power-to-Gas } \\ \text { WtG } & \text { Waste-to-Gas } \\ \text { MtG } & \text { Methanol-to-Gasoline } \\ \text { MtO } & \text { Methanol-to-Olefins } \\ \text { MtH } & \text { Methanol to Hydrocarbons }\end{array}$




$\begin{array}{ll}\text { WGS } & \text { Water Gas Shift } \\ \text { RWGS } & \text { Reverse Water Gas Shift } \\ \text { HTS } & \text { High Temperature Shift } \\ \text { LTS } & \text { Low Temperature Shift } \\ \text { MSW } & \text { Municipal Solid Waste } \\ \text { MRF } & \text { Material Recycling Facility } \\ \text { RDF } & \text { Refuse Derived Fuel } \\ \text { DFB } & \text { Dual Fluidised Bed } \\ \text { FICFB } & \text { Fast internally circulated fluidised beds } \\ \text { ASU } & \text { Air Separation Unit } \\ \text { CV } & \text { Calorific Value } \\ \text { HDS } & \text { Hydrodesulfurization } \\ \text { CCS } & \text { Carbon Capture Storage } \\ \text { CCSU } & \text { Carbon Capture Storage \& Utilization } \\ \text { PEM } & \text { Proton exchange membrane } \\ \text { FBG } & \text { Fluidised bed gasifier } \\ \text { PC } & \text { Plasma converter } \\ \text { KOP } & \text { Knock-out pot } \\ \text { FTIR } & \text { Fourier Transfer Infrared } \\ \text { PLC } & \text { Programmable Logic Controller } \\ \text { CEMS } & \text { Continuous Emissions Monitoring System } \\ \text { GSMR } & \text { Gas Safety Management Regulation } \\ \text { NEE } & \text { Net energy efficiency } \\ \text { WCE } & \text { Waste conversion efficiency } \\ \text { SOEC } & \text { Solid oxide electrolytic cells } \\ & \end{array}$

\section{INTRODUCTION}

Low molecular weight (LMW) hydrocarbons, such as methane, ethane and propane, are essential components in the world's energy mix. They provide low cost energy for a number of applications, such as on and off-grid heating, and produce lower levels of pollution and greenhouse gas (GHG) emissions when compared to conventional liquid fuels for transportation. The potential to generate large quantities of low carbon gas is essential for the future of the gas grid in Europe and worldwide [1]. Although most of developed countries have committed to reduce GHG emissions with the advances on wind and solar power sectors, the use of fossil gas for heating or transport still need to fall significantly [2]. Substitutes for fossil natural gas or liquefied petroleum gas (LPG) generated from renewable sources, such as biomass or waste, with different technologies (Figure 1) could play a decisive part in decarbonising both heat and transport in the future. Renewable gas is already produced in large volumes by anaerobic digestion (AD) of crops, agricultural residues and food waste [3]. During digestion, organic material is decomposed in an oxygen-free atmosphere by bacteria that produce a gas containing approximately two thirds methane, and one third carbon dioxide plus some impurities $\left(\mathrm{H}_{2} \mathrm{~S}, \mathrm{NH}_{3}\right)$ and water vapour. The biogas yield depends on different variables, including temperature, $\mathrm{pH}$ and feedstock composition, and can vary from $0.09-0.3 \mathrm{~m}^{3} / \mathrm{kg}$ of volatile solids in waste water residues, to $0.15-0.5 \mathrm{~m}^{3} / \mathrm{kg}$ for straw or pig slurry [4]. In order to feed biogas into the gas grid, the raw biogas has to undergo gas cleaning and $\mathrm{CO}_{2}$ separation, plus the addition of other LMW hydrocarbons (e.g. ethane or propane) to increase the heating value to match that of fossil natural gas $\left(37.5 \mathrm{MJ} / \mathrm{m}^{3}\right.$ to $\left.43.0 \mathrm{MJ} / \mathrm{m}^{3}\right)$. If $\mathrm{LMW}$ hydrocarbons additives could also be produced from renewable sources, the impact on carbon emissions would be even more favorable. Similar biological pathways are used to produce bioethanol, by fermenting sugars from starch and sugar biomass (e.g. sugarcane, sugar beet, etc.) [5]. Like in AD plants, the potential of bioethanol 
towards the intensification of renewable biofuels lies in its capacity to use alternative raw material including lignocellulosic material, such as herbaceous and woody biomass [6]. For example, based on average $42 \%$ cellulose and $21 \%$ hemicelluloses in waste wood, the maximum theoretical yield of bioethanol can be estimated to be around $30 \%$ in weight [7]. Similar experimental and simulated results are reported for the conversion of other nonfood biomass resources including corn stover, switch grass, sugarcane bagasse, and rice straw [8]. These second generation feedstocks do not pose any socioeconomic concerns because they are cheap, abundant and considered waste [9], [10]. However, the difficulty in processing these materials to bioethanol is that cellulose, together with hemicellulose and lignin, form a recalcitrant composite material, which requires costly pretreatment and hydrolysis processing [6]. Furthermore, second generation biofuels are hindered by low yields due to the formation of inhibitory compounds, which interfere with metabolic processes [6], [11].

Biodiesel, which has a chemical formula range between $\mathrm{C}_{10} \mathrm{H}_{20}$ to $\mathrm{C}_{15} \mathrm{H}_{28}$ with an average molecular weight $168(\mathrm{amu})$, is often the main product of biorefinery processes from which LMW hydrocarbons are recovered. Several technologies are well established to produce second generation biodiesel (fatty acid methyl esters - FAME) from transesterification of different feedstocks, including oil-bearing crops, cooking oils, non-edible oil crops, and animal fats [12]-[14]. The production of a higher quality biodiesel or a fraction of lighter hydrocarbons from the same feedstock is also possible by hydrodeoxigenation (HDO), or hydrotreatment [6], [15]. Fats and oil from plants are reacted with hydrogen at high pressure (40-150 bar) and temperature $\left(300-450{ }^{\circ} \mathrm{C}\right)$ in catalytic beds to produce a range of linear alkanes, from propane to naphtha, or further isomerized into biodiesel, synthetic paraffinic kerosene and waxes [10]. A number of LMW biofuels, including bioLPG (propane and butane), are being produced from vegetable oil and animal fats using commercial processes involving HDO reactors such as UOP's Ecofining process and NEXBTL's Renewable Diesel process [16]. In most cases bioLPG is recovered as byproducts from HVO (hydrotreated vegetable oil) or HEFA (hydrotreated esters and fatty acids) biodiesel production, with a biodiesel:bioLPG output ratio of about 9-10:1 in weight [17]. Despite this, hydroprocessing still requires a large amount of $\mathrm{H}_{2}$ (generally $300-420 \mathrm{~m}^{3} \mathrm{H}_{2} / \mathrm{m}^{3}$ vegetable oil), which is the main issue in the production of paraffinic hydrocarbons [15]. Furthermore, the potential of these processes is still limited by the availability of suitable feedstock.

New technologies that can process a wider range of materials, including unsorted biomass and municipal solid waste are required for LMW renewable fuels to make a meaningful contribution. The amount of municipal solid waste (MSW) produced worldwide is estimated to be 2 billion tons per year with a projected increase to 9.5 billion tons per year by 2050 [18]. Europe alone produced about 5.0 tonnes of waste per EU inhabitant in 2016, with more than $60 \%$ being landfilled or incinerated [19]. If the large biogenic fraction of MSW could be recovered or recycled using advanced thermal treatments, the contribution towards biofuels and decarbonization of the energy sector would be substantial. Advanced thermal treatments, gasification in particular, have great potential in this challenge due to the high feedstock flexibility and the possibilities to reduce significantly net $\mathrm{CO}_{2}$ emissions [20]. Light hydrocarbons can be produced as main or by-product of various gasification technologies, which involve the conversion of biomass or waste into a synthetic gas (a mixture of carbon monoxide and hydrogen, also known as syngas) before being further processed via catalytic stages into different products, including bioSNG (synthetic natural gas, mainly composed of methane and ethane), bio $\mathrm{b}_{2}$, bioLPG, biomethanol, etc. The most logical approach for the direct production of a range of lower alkanes from syngas is the typical $\mathrm{CO}$ hydrogenation process patented by F. Fischer and $\mathrm{H}$. Tropsch in Germany in 1925 [21]. Such process has been exploited for decades for the production of liquid fuels from coal, natural gas or biomass [22]-[24]. Other thermochemical pathways for hydrocarbon production from biomass include pyrolysis and subsequent hydrogenation [25], [26], hydrothermal liquefaction [27], Methanol-to-Gasoline [5], [28], and Methanol-to-Olefins processes [29], [30]. All these thermochemical pathways produce a broad range of products owing to the kinetic and thermodynamic factors that are in control. Translation of all these technologies to waste (or even biomass in some cases) however, presents a number of unique issues demanding specific design choices and technical solutions. For example, 
Waste-to-Fuel plants have to be significantly smaller operational scale than coal or natural gas plants (10-100 MWth compared with 1000s MWth) due to the complex nature of biomass and waste, and the lower energy density of the feedstock [31]. This has important implications for many aspects of the plant design, specifically the gas cleaning and hydrocarbons synthesis approach. Therefore, one of the issues facing the syngas generation and conversion processes is the development of technologies that can be scaled down to match the scattered nature of waste resources without compromising the overall plant efficiency. More recent developments have addressed this concern by focusing on the production of single carbon hydrocarbons, including bioSNG and biomethanol, which benefits from higher product selectivity and simplified product upgrading, making them competitive at small scale too. Recent examples are given by the Enerkem plant in Edmonton (Canada) [32] or the Gobigas project in Goteborgh (Sweden) [33]. Smaller plants are also more social acceptable and allows a greater degree of flexibility in terms of location. In fact, the reduced environmental impact due to the zero or low carbon impact, lower costs of feedstock transportation, along with the possibility to integrate with local heat and energy demand, and not last, their role in tackling the waste management problem, make them particularly attractive for modern urban environments. As part of this strategy, increasing production capacities for electricity generation from renewable sources (e.g. sun, wind, etc.) are also largely implemented, making the demand for energy storage capacity and process integration part of the agenda [34].

Presently, modular plants for selective production of LMW biofuels from waste via thermochemical routes are not commercially available. Estimated efficiencies are seemingly limited by the low hydrogen:carbon ratio of the feedstock and issues associated to scale of operation. Extensive work is needed to push forward commercial deployment of thermochemical waste processing plants by systematically working to address each barrier.

In this work the key design elements of existing gasification technologies that could be involved in converting waste into low molecular weight hydrocarbons (Waste-to-Gas process, or WtG), as well as the respective process designs, are identified and assessed (Section 2). A modular process suitable for waste treatment including, waste sorting, syngas generation, gas cleaning and catalytic transformation is examined, offering a range of process integration options. Differently from previous works focused on Biomass-to-Liquids (BtL) concepts, the plant scheme in this work is specifically tailored to maximize production of LMW biofuels, including bioSNG and bioLPG, starting from waste as a feedstock. Particular effort is put to highlight the biggest challenges in each of the conversion steps from waste to final product, also exploring the possibility to integrate the model with alternative low-carbon technologies for external hydrogen production. Finally, the results from a preliminary experimental campaign in a pilot plant are presented in Section 3. The results obtained are used for a first evaluation of a bioSNG commercial plant based on the current information available, but could be potentially extended to other LMW biofuel cases. 


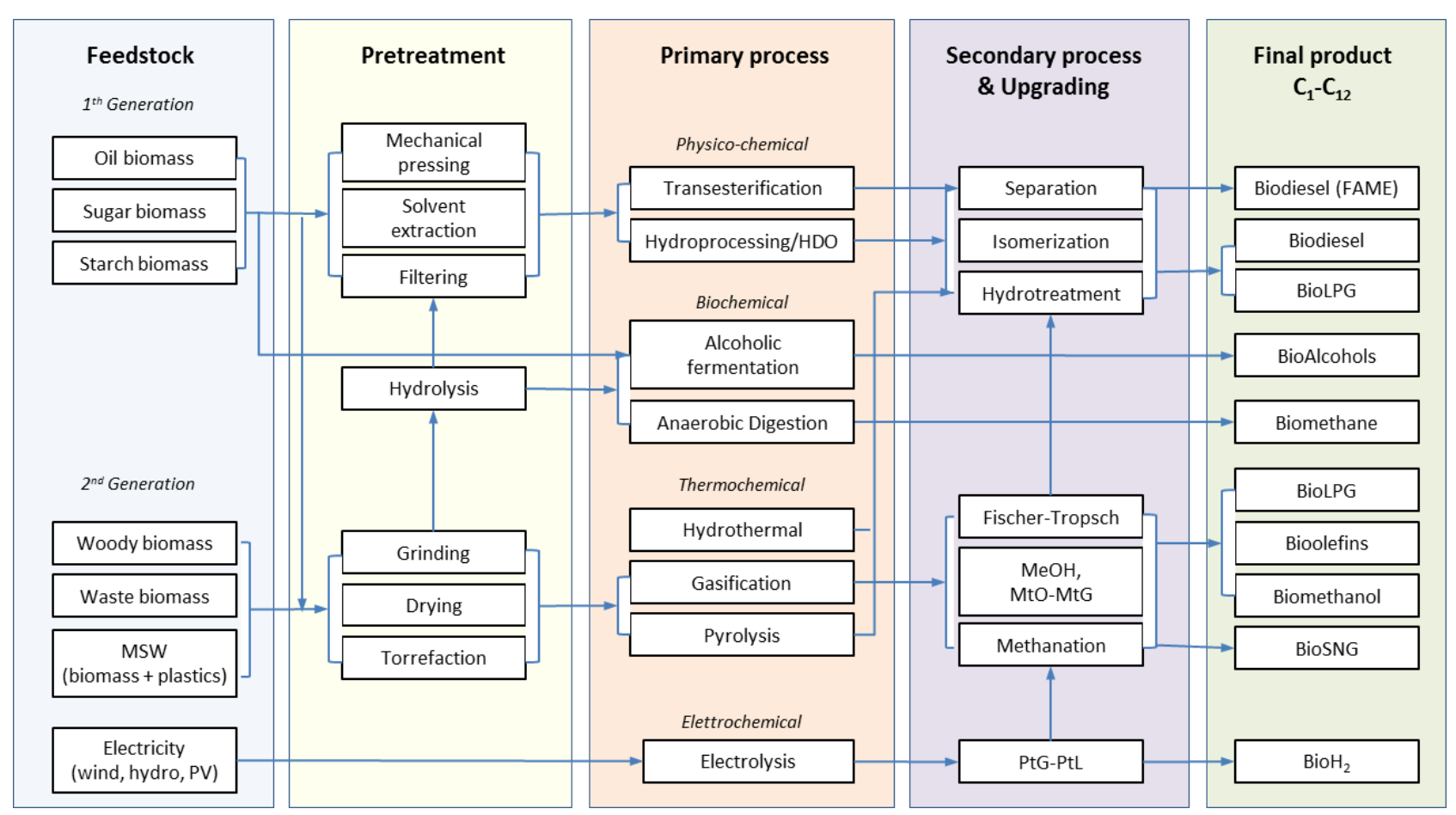

Figure 1: Overview of biological, chemical and thermochemical routes for production of low-molecular weight (LMW) biofuels from biomass

\section{WASTE-TO-GAS TECHNOLOGIES: CURRENT STATUS AND DESIGN CONSIDERATIONS}

In contrast to direct combustion (i.e. via mass burn incineration), gasification opens up a wide range of thermochemical options. It can unlock the potential of difficult heterogeneous waste materials, producing a homogenous multi-use energy carrier, thus forming the basis of the biorefinery concept. While the concept has traditionally focused on homogeneous coal or biomass, more difficult feedstocks, such as municipal and other solid waste streams, could find application. The overall process presented in this Section has focused on waste feedstocks, primarily MSW, as this represents the most technically challenging feedstock with the highest treatment costs, and will be the focus of early plants in the future. Feedstocks such as waste wood would require minimal process adjustments from conventional BtL plants, and have largely been discussed elsewhere [22], [35]. This section provides an overview of the main transformation steps for production of light biofuels from wastes and the specification for the baseline feedstock and conditions discussed in the final experimental section.

\subsection{RDF production}

Compared to biomass, MSW materials introduce a greater concentration and diversity of contaminants, due the large number and variability of sourcing points. This presents a major challenge, compounded by the fact that more sophisticated applications (including biofuel production) have far lower tolerances. Generally, the design point for the waste composition for a thermochemical facility is derived from a number of datasets for representative residual municipal, commercial and trade waste collected nationally as well as locally. An example of design point specification of waste in Western-England is as shown in Table 1. The untreated municipal or commercial waste is first mechanically processed in a materials recycling facility (MRF) at the front end. This is done to homogenise the material and remove part of the moisture, recyclables (for example, metals and dense plastics) and reject materials (for 
example, oversize and inerts). The material is then shredded using tearing motion to achieve a rough shred of untreated waste, with a homogenous, pre-determined particle size between 1-50 mm, depending on the gasification reactor requirements. The final feedstock is in the form of floc wet RDF (Refuse Derived Fuel), which is then dried on-site using waste heat from the process; the data presented on Table 2 gives an indicative specification for the RDF, based on the waste described in Table 1. Typically, a 150,000 tonnes MSW feed produces an output of ca. 90,000 to 120,000 tonnes of RDF with a moisture content of $10-17 \%, 10-20 \%$ ash content and 15-25 MJ/kg calorific value (CV).

A key parameter for understanding the renewable attributes of the biofuel produced is the biomass content of the feedstock; the biomass content of RDF consists of its biodegradable fraction and is usually represented by the percentage of biogenic carbon (C-14) in comparison to the total carbon present in RDF, or as renewable energy fraction of the total calorific value of the feedstock (which also includes fossil derived components, like plastics). The default assumption used for the Renewables Obligation Order in the UK is a biomass content of at least $50 \%$ (on energy basis); for simplicity, the prefix "bio" is added in this work to any synthetic fuel whose original biogenic carbon content exceeds this percentage.

Table 1 Design point waste composition from local suppliers (Swindon, UK)

\begin{tabular}{c|c|c|c}
\hline Category & Design Point & Lower limit & Upper limit \\
\hline Paper (wt\%) & 30.36 & 19.47 & 64.00 \\
Plastic Film (wt\%) & 5.72 & 3.55 & 17.80 \\
Dense Plastics (wt\%) & 8.38 & 5.50 & 16.20 \\
Textiles (wt\%) & 3.64 & 0.20 & 8.17 \\
Disposable Nappies (wt\%) & 4.91 & 0.00 & 8.00 \\
Misc Combustible (wt\%) & 6.40 & 2.29 & 10.92 \\
Misc Non-Combustible (wt\%) & 6.08 & 0.00 & 8.93 \\
Glass (wt\%) & 7.01 & 0.60 & 11.00 \\
Putrescible (wt\%) & 16.82 & 3.00 & 27.00 \\
Ferrous (wt\%) & 6.61 & 1.10 & 11.69 \\
Non-ferrous (wt\%) & 1.96 & 0.60 & 2.90 \\
Fines (wt\%) & 2.13 & 1.00 & 5.50 \\
\hline Total & 100.00 & & 13.62 \\
\hline CV (MJ/kg) & 10.05 & 9.08 & 80.1 \\
RDF biomass content (wt\%) & 67.7 & 49.1 & 79.8 \\
\hline
\end{tabular}

Table 2. RDF proximate and ultimate analysis. RDF (as received)

\begin{tabular}{ll}
\hline & RDF (as received) \\
\hline Proximate analysis, \% $(w / w)$ & \\
Fixed carbon & 6.4 \\
Volatile matter & 59.6 \\
Ash & 19.1 \\
Moisture & 14.9 \\
Ultimate analysis, \% $(w / w)$ & \\
$\mathrm{C}$ & 41.0 \\
$\mathrm{H}$ & 5.7 \\
$\mathrm{O}$ & 17.5 \\
$\mathrm{~N}$ & 1.2 \\
$\mathrm{~S}$ & 0.2 \\
$\mathrm{Cl}$ & 0.4 \\
$\mathrm{GCV}, \mathrm{MJ} / \mathrm{kg}$ (dry basis) & 22.1 \\
\hline
\end{tabular}




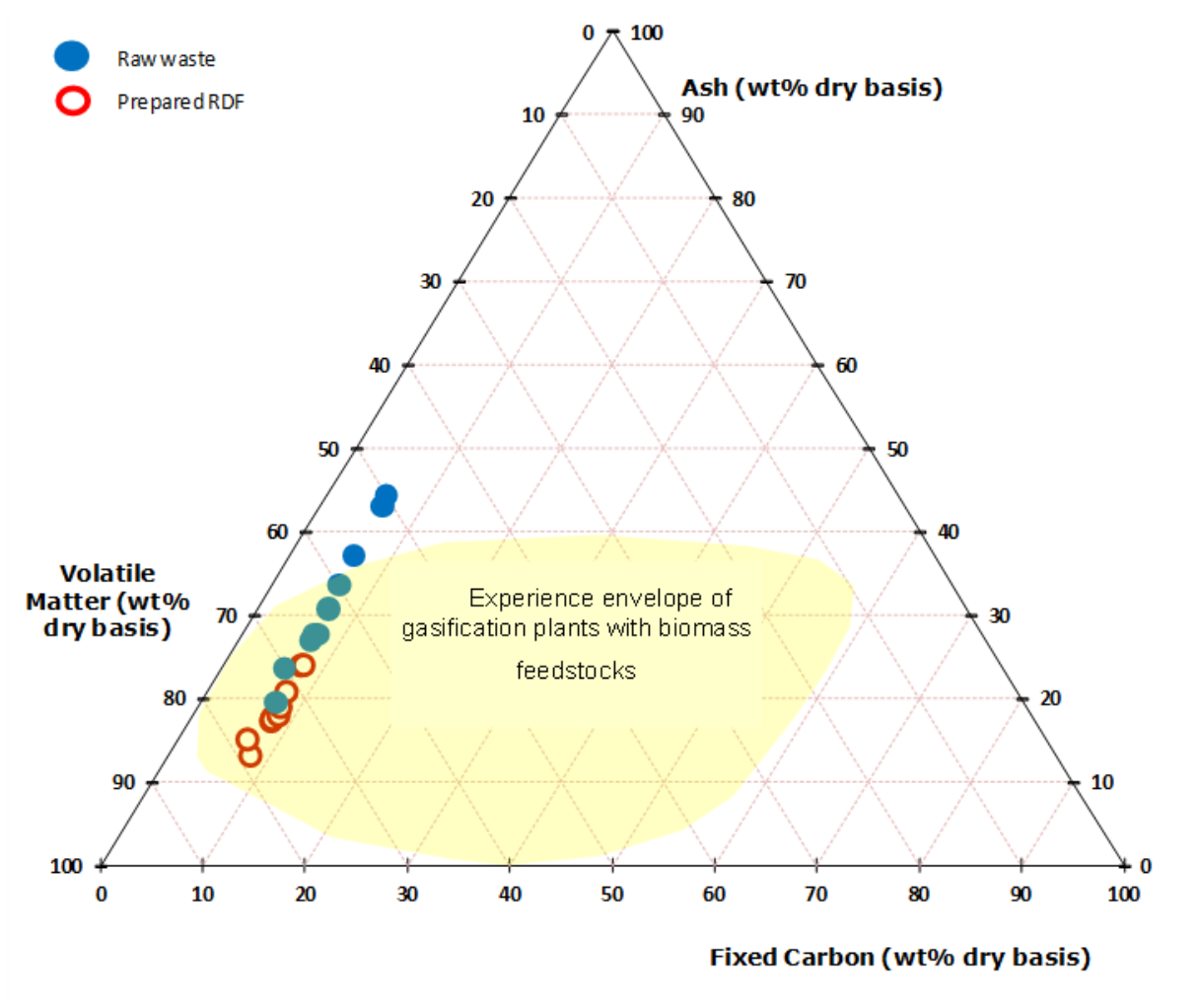

Figure 2: Ternary diagram of waste and RDF composition, and area of conventional feedstock application

A series of waste compositions derived from waste audits are shown in Figure 2, along with an illustrative "area of experience" of commercial plants on generic biomass feedstock [36]. This shows also the "averaging" affect of the fuel preparation plant on the waste, with the prepared RDF showing considerably less variability than the raw waste. As can be readily appreciated, RDFs are characterized by high moisture, ash and volatile content, and a porous-fragile structure. These features reflect the propensity of such fuel to give rise to large quantities of tars evolved and a multitude of fine fragments of carbon and fly-ash particles when entering the gasification stage, making them difficult to treat in conventional technologies [37].

\subsection{Syngas generation}

A key element for a consistent quantity of hydrocarbons generation is the production of a high quality syngas suitable for catalytic processing. Ideally this syngas is free of poisoning contaminants (sulphur and chlorine), tars and nitrogen, the latter difficult to remove from a gas stream product. In order to get the right syngas, both autothermal and allothermal processes can be used. The chemistry and form of the feedstock, as well as scale, means that unlike coal, RDF cannot be processed using established high intensity technologies, like for example entrained flow gasification [38]. Due to their flexibility and robustness, fluidised bed gasifiers (FBG) are instead more suitable for small applications and for treating gross and etherogeneous feedstock [39]. They have been successfully applied for the gasification of RDF and other waste materials [40]-[42], mixed plastics [43], [44], and waste biomass [45], [46]. For BtL or Waste-to-Gas applications, autothermal FBG processes are carried out with pure oxygen as gasification agent. In the first case, pure oxygen is preferred to air as the process normally contains recycle loops in which nitrogen will tend to accumulate. In WtG applications, nitrogen needs to be avoided as it would be difficult to be separated from the final gas product [38]. In order to deliver sufficient pure oxygen without producing high temperatures, oxygen/steam mixtures are typically used in practical applications [47]. This 
will result in a product gas with medium calorific values, no nitrogen, and low hydrocarbon contents (mostly methane) in the product gas. The $\mathrm{H}_{2}: \mathrm{CO}$ ratio is important for further catalytic hydrogenation to bio-hydrocarbons and this ratio in case of oxygen/steam gasification will be in the order of 1.0 to 1.5 depended on biomass steam ratio [48]. As temperature within the bed has to be limited to below ash softening point, upstream oxygen enrichment can also be used, although issues arise for the potential hazards associated with oxygen-rich mixtures at high temperatures [49].

Allothermal gasification processes will typically use steam (or in future $\mathrm{CO}_{2}$ ) as gasification agents in an externally heated reactor (e.g. plasma or heat pipe reactors), fast internally circulated fluidised beds (FICFB) or dual fluidised beds (DFB) [46], [49]. In this latter configuration, air is used to burn char and/or secondary fuels in a fluidised bed to provide heat to an inert bed material (e.g. sand) which is then transferred to a second oxygen-starved FBG running in parallel on pure steam $\left(\right.$ or $\left.\mathrm{CO}_{2}\right)$. Since the process is split in two separate chambers, the produced syngas is not diluted with products of combustion, and $\mathrm{CO}_{2}$ and $\mathrm{N}_{2}$ content within the syngas is remarkably low. The use of steam as gasification agent leads to medium calorific values, medium-to-high hydrocarbons content in the product gas, and also to the highest ratio of $\mathrm{H}_{2}: \mathrm{CO}$ (approx. 1.5-2.0) of all gasification processes. $\mathrm{CO}_{2}$ as gasification agent compared with steam will lead to lower hydrogen and higher carbon monoxide contents and consequently to an essential lower ratio of $\mathrm{H}_{2}: \mathrm{CO}$. Allothermal FBGs have the advantage of working with no need of an air separation unit (ASU) for oxygen production, thus reducing significantly the operation costs of the plant.

A combination of autothermal and allothermal processes can also be used for advanced thermal treatment of waste feedstock. For example, waste gasification can be performed in a two-stage steamoxygen gasifier and subsequent plasma converter for high quality syngas generation [50]. The use of plasma has increasingly been applied with waste treatment for its ability to completely decompose the input material into a tar-free synthetic gas and an inert, environmentally stable, vitreous material known as slag. The principal advantages that plasma offers to thermal conversion processes, besides the already mentioned tar/ash related issues absence, are a smaller installation size for a given waste throughput, and the use of electricity as energy source, characteristics which permit the technology to treat a wide range of heterogeneous and low calorific value materials including various hazardous waste, such as PCBs, medical waste, and low-level radioactive [51]-[53]. Vitrified ashes show excellent mechanical and anti-leaching properties, and are suitable as a construction material [52]. The two-stage process is particularly suitable for processing waste feedstock due to the high quantity of ash, organic and inorganic contaminants, and typical fluctuating quality of the feedstock. However, the presence of an ASU and plasma electrode make the process particularly energy intensive when compared to standalone allothermal reactors (i.e. dual fluidised beds), which are normally the favourite option in biomass applications, where ash content is a lower issue.

\subsection{Gas cooling and cleaning}

The cleaning of the syngas from contaminants arising from components of the waste down to values that are acceptable for different downstream catalysts are of crucial importance for successful implementation of waste gasification technology, and in particular Waste-to-Fuel applications. Syngas exits the gasification stage at temperature usually higher than $800{ }^{\circ} \mathrm{C}$ (or at $1000-1200{ }^{\circ} \mathrm{C}$ if a second thermal stage is used) comprising mostly of $\mathrm{H}_{2}, \mathrm{CO}, \mathrm{H}_{2} \mathrm{O}$ and $\mathrm{CO}_{2}$ and a number of contaminants, before passing through a steam boiler where it is cooled to $200^{\circ} \mathrm{C}$. The steam generated can be used within the process and to generate electricity using a steam turbine. After heat recovery and tar removal, the syngas has to pass through a gas cleaning system to remove residual particulates, vapour phase metals, with Mercury being of primary concern, and acid gases ( $\mathrm{Cl}$ - and $\mathrm{S}$ - based compounds). Chemical absorbents for gas phase cleaning are typically contained in fixed bed reactors, however if the contaminant levels are high, or if the contaminants cannot easily be removed by a fixed bed, a recycle liquid scrubbing system may be a more appropriate process scheme followed by fixed bed 'polishing' treatments. The use of liquid 
scrubbers requires that the gas temperature is further cooled down to $<80{ }^{\circ} \mathrm{C}$ placing additional requirements on the gas conditioning train. Typical cleaning system for small scale $(<100 \mathrm{MW})$ biomass or waste based plants will include tar removal systems (for single stage gasification), dry filters (incorporating a ceramic filter unit with chemical sorbents dosing), and alkaline wet scrubbers. The clean syngas $\left(\mathrm{CV}=10-14 \mathrm{MJ} / \mathrm{Nm}^{3}\right)$ is dewatered before being further polished in a series of guard beds for removal of residual catalytic process poisons, including dehalogenation, olefins hydrogenation, deoxygenation and $\mathrm{H}_{2} \mathrm{~S}$ and organo-S components removal using Hydrodesulphurization (HDS). A list of contaminants tolerance for major catalytic processes is reported in Table 3

Table 3:. Contaminant tolerance for select syngas applications [54]

\begin{tabular}{l|l|l}
\hline Contaminant & Application \\
\hline & FT synthesis & Methanol synthesis \\
\hline S-compounds & $<1 \mathrm{ppm}, 20 \mathrm{ppb}$ & $<1 \mathrm{ppm}, 0.1 \mathrm{ppmv}$ \\
Halogens $(\mathrm{HCl}, \mathrm{HF})$ & $<10 \mathrm{ppbv}$ & $<10 \mathrm{ppbv}$ \\
$\mathrm{N}$-compounds & $<1 \mathrm{ppm}, 20 \mathrm{ppb}$ & $10 \mathrm{ppmv} \mathrm{NH}, 0.01 \mathrm{ppmv}$ \\
Alkaline metals & $<10 \mathrm{ppbv}$ & - \\
Heavy metals & $<10 \mathrm{ppbv}$ & $<10 \mathrm{ppbv}$ \\
Tar and BTX & Below dew point & Low \\
Particles & $0.1 \mathrm{mg} / \mathrm{Nm}^{3}$ & $0.02 \mathrm{mg} / \mathrm{m}^{3}$ \\
\hline
\end{tabular}

As a general rule most catalytic processes require a level of the contaminant in the gas phase to be below $0.1 \mathrm{ppm}$ to be considered acceptable for commercial use. In the case of Mercury vapour this is generally required to be below $10 \mathrm{ppb}$ to be acceptable. The adsorbent of choice is therefore required to operate under the relevant process conditions and to remove and isolate the poison without further reactions from gas stream components. The nature of the material used for poisons removal is largely dependent on process conditions and in general a high surface area coupled with a high bulk density is advantageous, assuming that the narrower pores that go with increased surface area and density are not blocked at the pore mouth in use. The process methodology applied to remove the poison is largely dependent on the level of contamination. Sulphur is the primary catalyst poison as the sulphides of the active metals are stable under process conditions, thereby modifying and attenuating the process catalytic activity required. Sulphur compounds are widespread in waste derived syngas and the higher molecular weight compounds (i.e. thiophenes/benzothiophenes) are reasonably refractory, requiring plasma reforming or HDS hydrotreatment to be removed. Secondary poisons are the metal hydrides (Mercury/Arsenic/Phosphorus/Selenium) and acid gas components (HS-O/HF/HCL). Tertiary poisons are the Aromatics and Olefins which give rise to polymeric and carbon deposits on the catalyst surface. This is particularly the case for the precious metals, Nickel, Copper and Iron based catalysts used for biofuels generation [55]. For economic reasons at small scale, the organic sulphur, unsaturated hydrocarbons (e.g. ethylene, acetylene, etc.) and light aromatics arising from lower intensity gasification cannot be removed using physical solvent scrubbing such as Rectisol, and thermal or hydrothermal technologies are used. An extensive review of gas cleaning methods for syngas polishing can be found elsewhere [56]-[58].

\subsection{Gas conditioning}

Typical synthesis gases have a $\mathrm{H}_{2}: \mathrm{CO}$ ratio in the range of 0.5 to 1 . Since syngas hydrogenation for LMW hydrocarbons synthesis requires a hydrogen to carbon monoxide ratio comprised between 2:1 (FT) to $3: 1$ (generic alkanation), the ratio of hydrogen to carbon monoxide in the synthesis gas is typically increased prior to hydrogenation by reacting a portion of the carbon monoxide with water to produce hydrogen and carbon dioxide. This is known as the "water-gas-shift" WGS reaction. 
In conventional BtL plants water gas shift occurs in a single stage reactor with an Iron based catalyst operated at approximately $350-400{ }^{\circ} \mathrm{C}$ (HTS Catalyst). Chromium oxide, $\mathrm{Cr}_{2} \mathrm{O}_{3}$, is also added to prevent the sintering of iron oxide crystallites. If the syngas has been cleaned of primarily $\mathrm{S}$ and $\mathrm{Cl}$ poisons, then a Copper based catalyst may also provide additional WGS activity at lower temperatures than Iron (LTS Catalyst). Super-heated steam is added to the syngas in the quantity needed to achieve the desired $\mathrm{H}_{2}$ :CO ratio. Whilst the WGS reaction has been historically used to increase the $\mathrm{H}_{2}: \mathrm{CO}$, and hence the amount of HCs formed during the subsequent hydrogenation, it results in around one to two thirds of the carbon content of the synthesis gas being jettisoned from the process as $\mathrm{CO}_{2}$. If carbon capture and storage (CCS) or utilisation (CCSU) strategies are not adopted, this results in the process being chemically wasteful (especially considering the potential of biogenic waste-derived $\mathrm{CO}_{2}$ ).

In order to overcome this problem of carbon rejection via the WGS, the ratio of hydrogen to carbon monoxide can be instead controlled by externally generating hydrogen gas and then adding the hydrogen gas to the synthesis gas. This has the twofold function of adjusting the $\mathrm{CO}: \mathrm{H}_{2}$ ratio to the desired values and also providing excess $\mathrm{H}_{2}$ to hydrogenate $\mathrm{CO}_{2}$ to more $\mathrm{LMW}$ hydrocarbons, thus maximizing product generation. The hydrogen gas can be generated by the electrolysis of water, which has been achieved using electricity from low carbon sources (e.g. wind, solar, etc.) during times of excess generation and/or low peak demand [59].

Anode reaction: $\quad 2 \mathrm{H}_{2} \mathrm{O}(\mathrm{l}) \rightarrow \mathrm{O}_{2}(\mathrm{~g})+4 \mathrm{H}^{+}(\mathrm{aq})+4 \mathrm{e}^{-}$

Eq.2

Cathode reaction: $\quad 4 \mathrm{H}^{+}(\mathrm{aq})+4 \mathrm{e}^{-} \rightarrow 2 \mathrm{H}_{2}(\mathrm{~g})$

Eq.3

Global reaction: $\quad 2 \mathrm{H}_{2} \mathrm{O}(\mathrm{l}) \rightarrow 2 \mathrm{H}_{2}(\mathrm{~g})+\mathrm{O}_{2}(\mathrm{~g})$

This principle is similar to that applied as Power-to-Gas (PtG) or Power-to-Liquids (PtL), used in Germany and France to create a new level of flexibility into the energy supply and to maximize the proportion of energy from renewable sources. Similar integration approaches have also be examined by several authors [59]-[62]. If the power is derived mainly from renewable power sources, only low-carbon hydrogen will be produced which in turn could allow full recovery of the carbon atoms $\left(\mathrm{CO}+\mathrm{CO}_{2}\right)$ present in the syngas. Another important feature of the PtG unit is that it also produces pure oxygen which can be fed directly back to the gasification stage, thereby reducing the burden on the ASU in case of autothermal gasification. For example, assuming a commercial proton exchange membrane (PEM) electrolyser efficiency to be $80 \%, 4500 \mathrm{kWh}$ of electricity would produce approximately $1000 \mathrm{Nm}^{3}$ of hydrogen and $500 \mathrm{Nm}^{3}$ of oxygen. This would be enough to meet the full supply of oxygen for a small scale $10 \mathrm{MW}$ th gasification plant. Alternatively, as $250 \mathrm{kWh}$ of electricity is required for oxygen production of $500 \mathrm{Nm}^{3}$ by cryogenic air separation, the full utilization of by-product oxygen from the electrolyser corresponds to the reduction of electricity consumption of up to $10 \%$ in a larger $100 \mathrm{MW}$ th gasification plant. Obviously electrolysis itself is not attractive for producing oxygen and cannot compete yet with commercial technologies. The by-product oxygen might, however, be useful for making the PtG hydrogen production attractive in an integrated WtG-PtG approach.

\subsection{Catalytic synthesis}

Biomass or waste-based clean syngas can be reformed to a range of LMW hydrocarbons using the well-established Fischer-Tropsch (FT) technology, which involves synthesising syngas into gaseous hydrocarbons by passing the syngas through a reactor containing catalysts [54], according to the following equation:

$(2 \mathrm{n}+1) \mathrm{H}_{2}+\mathrm{n} \mathrm{CO} \rightarrow \mathrm{C}_{\mathrm{n}} \mathrm{H}_{(2 \mathrm{n}+2)}+\mathrm{n} \mathrm{H}_{2} \mathrm{O}$

For $n=1$ Eq. 5 is commonly known as methanation, while higher integer values are typical of Fischer 
Tropsch (FT) reactions. Such reactions are highly exothermic, and appropriate control strategies and reactors design have to be adopted to avoid reaction runaway. These include dilution of reactants and catalysts, staged feeding and product recirculation.

The synthesis of liquid hydrocarbons from syngas via FT is a well-known process already under use throughout the world in coal and natural gas-based (CtL, GtL) plants. However, the output of LMW hydrocarbons from this process is relatively small, at a few per cent of the total hydrocarbons output [63]. In fact the strategy selected by current commercial FT plants has been to maximise thermodynamically the production of $\mathrm{C} 21+$ fraction (wax) via low temperature FT synthesis, minimising the formation of undesired light products. Subsequently, the wax molecules are converted into the most desired diesel fraction via hydrocracking processes, and the residual light fraction burnt for steam generation or recycled to the process. Such strategy might not be efficent in a smaller scale plant, which would require a simplified approach. For example, in case the lower end of the HC spectrum is desired, high temperature and larger hydrogen content (along with other factors) would favour an early chain termination. At these conditions wax production is drastically reduced, and a hydrocracking stage might not be required. Furthermore, higher operating temperatures and hydrogen content allow for higher conversion of syngas per pass through the catalytic bed, making expensive gas recycling systems an unnecessary requirement. Several reviews of FT catalytic processes for the production of light alkenes from biomass syngas have been published in the last years [29], [64], and results are promising.

$\mathrm{Fe}, \mathrm{Co}, \mathrm{Ni}$ and $\mathrm{Ru}$ are active catalysts for FT, but only Fe and Co are used extensively for typical FT reactions (whilst Nickel is mostly used for syngas methanation). Although Ruthenium exhibits excellent activity for FT reactions, its limited availability and cost prohibits its use as a standalone catalyst on an industrial scale.

Iron based catalysts have been shown to be active for the formation of hydrocarbons at higher reaction temperatures (300-350 ${ }^{\circ} \mathrm{C}$ ), but suffer from complex phase formation and deactivation by water [65]. The possibility of using iron-based catalysts is particularly appealing when the syngas is not conditioned through a dedicated WGS step, as this reaction (Eq.1) occurs naturally within the FT synthesis on iron. In addition, iron catalysts have been reported to display a much higher resistance to typical syngas contaminants, and can therefore potentially be applied in waste gasification plants. These two advantages of iron-based catalysts, which imply the potential removal of the syngas conditioning step and less stringent gas cleaning requirements, in combination with their low price, could potentially lead to significant cost savings and better prospects of integration with WtG and PtG plants.

Cobalt is used as an FT catalyst because of its resistance to deactivation and efficiency for long chain hydrocarbon synthesis [66]. Cobalt catalysts are active at lower temperatures than Fe and tend to produce light hydrocarbons, particularly when promoted with manganese oxide. A range of studies have been published on $\mathrm{CoMnOx}$ catalysts for the synthesis of light hydrocarbons, and they demonstrate lower selectivity to methane [67]. It has been observed that $\mathrm{Co}$ in combination with manganese oxide can produce high yields of alkenes with increasing $\mathrm{CO}$ conversion, whereas this is not observed with cobalt only catalysts. The use of partially reducible oxides such as $\mathrm{MnO}_{2}$ and $\mathrm{TiO}_{2}$ has been shown to improve the selectivity towards light alkenes in FT using cobalt as the active metal component [64]. Although $\mathrm{H}_{2}$ :CO ratios close to 1 are normally accepted for liquid productions, a greater excess of $\mathrm{H}_{2}$ is expected to be needed for shorter chain hydrocarbons.

Another possible route that can be considered for the conversion of syngas to form LMW hydrocarbons is by utilising a combination of catalysts comprising of a methanol synthesis catalyst (Cu based on Zinc oxide support) and a zeolite [28]. Zeolites can be employed as catalysts in various important chemical reactions such as isomerisation, cracking and synthesis of hydrocarbons. They possess the ability to promote metal induced reactions as well as acid base reactions. The reactions occur inside the pores of the zeolite which can greatly help in controlling the selectivity of the desired product. ZSM-5 zeolites have been extensively used to convert methanol to diesel [68]. The hybrid catalysts consisting of a mixture of zeolite and the methanol synthesis catalyst $(\mathrm{Cu}-\mathrm{ZnO})$ have also been utilised for the production of LPG [69], [70]. Other hybrid catalysts employed for the synthesis of light biofuels like LPG and gasoline include $\left(\mathrm{Pd}-\mathrm{Ca} / \mathrm{SiO}_{2}\right) / \beta z e o l i t e$ [71] and $\mathrm{Pd} / \mathrm{ZnO} / \mathrm{Al}_{2} \mathrm{O}_{3}-\mathrm{HZSM}-5$ [72] respectively. This process belongs to the 
more general group, methanol-to-hydrocarbons $(\mathrm{MtH})$, which also comprises the methanol-to-gasoline (MtG) and methanol-to-olefin (MtO) processes [22]. The criterion for discrimination is the choice of catalyst and reaction conditions. In all cases, the first step is the production of methanol, which is a proven industrial process. The catalyst used is a copper-zinc oxide complex, stabilized and strengthened with alumina $\left(\mathrm{Cu} / \mathrm{ZnO} / \mathrm{Al}_{2} \mathrm{O}_{3}\right)$. The catalyst is highly selective and gives a methanol purity $>99.5 \%$ [28]. The desired operation conditions with this catalyst are relatively low pressure (5-10 bar) and temperature $\left(200-250^{\circ} \mathrm{C}\right)$. The total conversion of $\mathrm{CO}$ (from syngas to hydrocarbons) varies from $73 \%\left(250^{\circ} \mathrm{C}, 5 \mathrm{bar}\right)$ to $99 \%\left(200^{\circ} \mathrm{C}, 10 \mathrm{bar}\right)$ [22], and the overall reactions can be summarised as:

\begin{tabular}{lr}
$\mathrm{CO}+2 \mathrm{H}_{2} \leftrightarrow \mathrm{CH}_{3} \mathrm{OH}$ & Eq.6 \\
$2 \mathrm{CH}_{3} \mathrm{OH} \leftrightarrow \mathrm{CH}_{3} \mathrm{OCH} \mathrm{H}_{3}+\mathrm{H}_{2} \mathrm{O}$ & Eq.7 \\
$\mathrm{CH}_{3} \mathrm{OCH} \mathrm{H}_{3} \rightarrow$ light hydrocarbons $+\mathrm{H}_{2} \mathrm{O}$ & Eq.8 \\
$\mathrm{H}_{2} \mathrm{O}+\mathrm{CO} \leftrightarrow \mathrm{CO}_{2}+\mathrm{H}_{2}$ & Eq.1 \\
\hline $2 \mathrm{nCO}+(\mathrm{n}+1) \mathrm{H}_{2} \leftrightarrow \mathrm{C}_{n} \mathrm{H}_{2 n+2}+\mathrm{nCO}_{2}$ & Eq.9
\end{tabular}

As for FT processes, a syngas $\mathrm{H}_{2}: \mathrm{CO}$ ratio of $>2$ is required. The $\mathrm{CO}_{2}$ normally present in the syngas mixture is beneficial to methanol production as long as it is limited to below $10 \%$ vol. [30]. In fact, the presence of $\mathrm{CO}_{2}$ accelerates the methanol synthesis reaction but higher concentrations decrease the catalyst activity by reversing the overall equilibrium. In this sense, we already envisage that avoiding the WGS step for $\mathrm{H}_{2}$ : $\mathrm{CO}$ adjustement, which itself produces more $\mathrm{CO}_{2}$ at the expenses of $\mathrm{CO}$, would provide a better opportunity to maximise product yield and reactors efficiency in the integrated thermochemical process.

\subsection{Product upgrading}

In order to get high syngas conversion (>90\%), sequential catalytic stages might be needed in an integrated $\mathrm{WtG}$ process. This is particularly true if a recycling stream is to be avoided, thus simplifying significantly the layout of the process and the handling of the inert components. Product water and any other liquid condensate need to be knocked out after each reactor, in order to keep partial pressure of reactants sufficiently high. With $50-60 \%$ conversion in each reactor, a total once-throught $\mathrm{CO}$ conversion of $95 \%$ is achievable in 3 consecutive stages [22].

For both FT and $\mathrm{MtH}$ processes the final step is the product separation, which mostly depends on the scale of the plant, products distribution and final product market. In a typical FT plant the products are fractionated in a conventional distillation section. The fraction boiling above the gas oil range is recycled back to the process, either in the synthesis or hydrorefining stage, while the rest is recovered as naphta

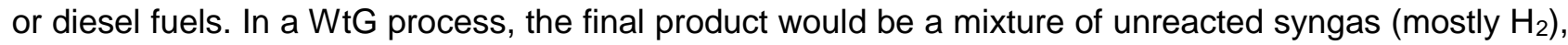
$\mathrm{CO}_{2}$, and light hydrocarbons. The heaviest fraction of this that can be recovered as naphta or be further cracked into shorter chains. Light gases are cooled to separate bioLPG (C3-C4), with the rest being sold as a mixture of hydrogen and SNG (bioSNG- $\mathrm{H}_{2}$ ). Non-hydrocarbon compounds, including $\mathrm{CO}_{2}$ and $\mathrm{N}_{2}$, can be retained in the lightest fraction, provided they are in low levels and do not overdilute the product. If significant amount of $\mathrm{CO}_{2}$ remains in the offgas, this can be separated and stored for further hydrogenation should excess of $\mathrm{H}_{2}$ be available.

Similarly, in a $\mathrm{MtH}$ plant, the reactor effluent is cooled to $25-35^{\circ} \mathrm{C}$ and passed to the product separator, where gas, liquid hydrocarbons and water are separated. The liquid hydrocarbon product (raw gasoline) contains mainly gasoline boiling range material. The $\mathrm{C1-4}$ fraction is removed by distillation. Also in this case, a significant amount of $\mathrm{CO}_{2}$ might be retained in the gaseous product stream. The debate on whether the $\mathrm{CO}_{2}$ would be better removed before or after the catalytic step remains open. On the one hand, the $\mathrm{CO}_{2}$ can be removed upstream and stored, thus reducing the amount of gas troughput in the catalytic stages (and associated costs of compression). This could be advantageous if $\mathrm{CO}_{2}$ acts only as 
a diluent within the syngas, or worse if it inhibits $\mathrm{CO}$ hydrogenation. $\mathrm{CO}_{2}$ can then be hydrogenated separately or converted to $\mathrm{CO}$ should excess $\mathrm{H}_{2}$ be available, using commercially available solutions [73]. On the other hand, $\mathrm{CO}_{2}$ can play an important role in controlling the exothermic reactions within the catalytic steps, by providing a mean to extract heat from the catalyst particles. Finally, $\mathrm{CO}_{2}$ could react with excess $\mathrm{H}_{2}$ within the same system thus maximising product yield in a fully operational PtG-WtG integrated system.

A summary of all processing steps involved in a conventional and integrated thermochemical routes for short chain hydrocarbons production from solid feedstock is illustrated in Figure 3.

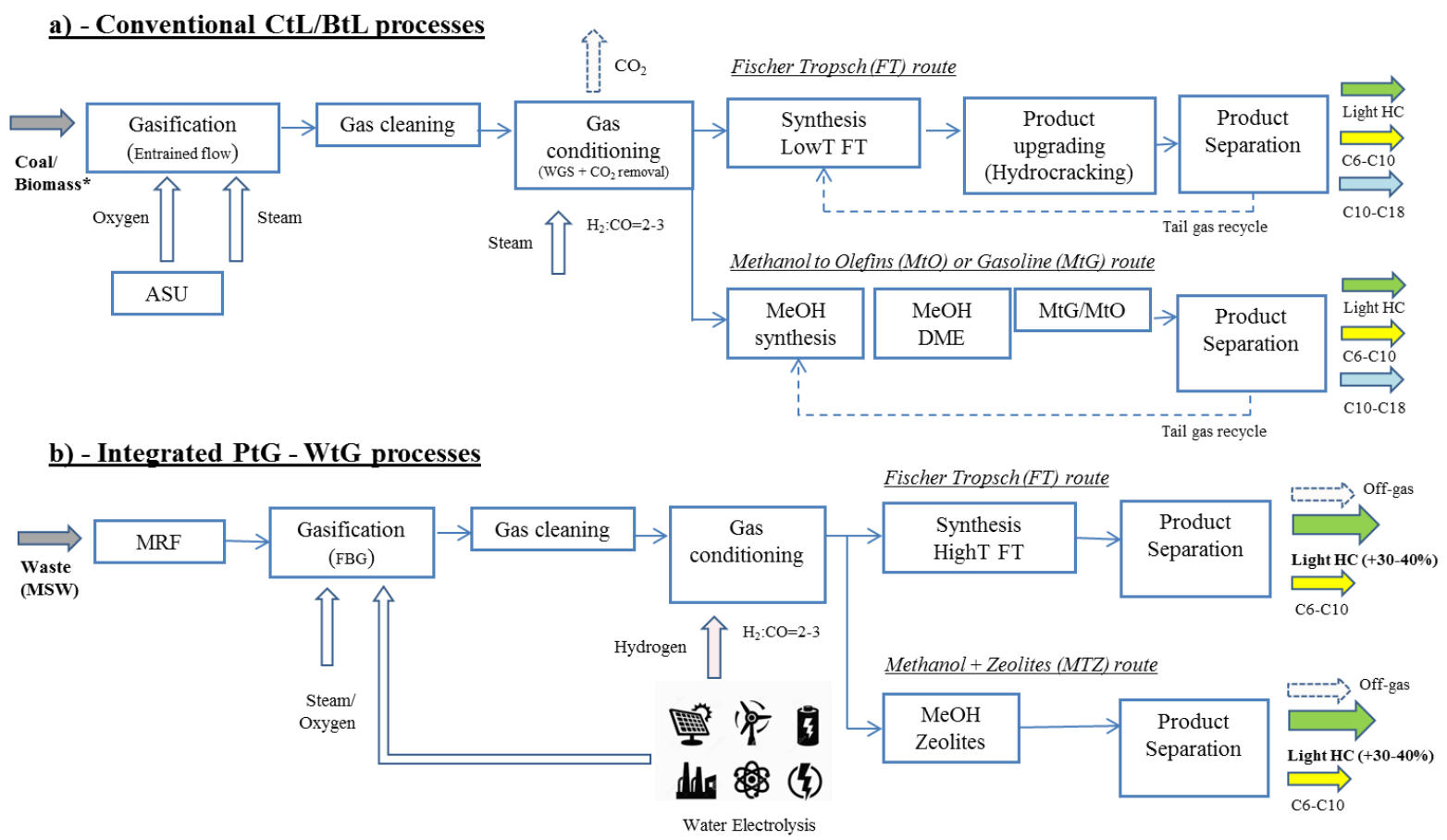

Figure 3 Simplified schematics of conventional (a) and integrated routes (b) for light hydrocarbon production via gasification

\section{EXPERIMENTAL}

An experimental campaign has been undertaken to prove the suitability of the integrated process and a preliminary assessment has been made in this work. In order to avoid excessive boundary layer effects and provide a representative behavior of waste gasification and gas cleaning in commercial integrated plant, syngas generation experimental tests would ideally be performed in a moderately large scale facility. Unless this is done, the process performance projections would be just extrapolations from small lab-scale apparatus and unrepresentative waste samples, with major uncertainty associated with the usage of unvalidated models. However, testing on smaller scale experimental facilities for the subsequent syngas transformation route was recognised as equally important for this study. In the first instance, such an approach enables tight control and easily changed experimental conditions (flux rates, gas compositions, pressures and temperatures), and quick change out of catalysts, so different catalysts can be readily evaluated. Furthermore, by operating a small single tubular catalytic reactor (resembling the size of one tube of a typical FT shell-and-tube bundle), sustained and prolonged operation was possible, enabling to see the impact (if any) of trace contaminants from waste derived syngas on the catalyst activity.

The configuration of the combined experimental facilities is illustrated in Figure 4. This includes the 
schematics of the pilot plant used for syngas generation, cleaning and compression, and that for the offline experimental rig (synthesis reactor) for syngas testing and LMW biofuel production.

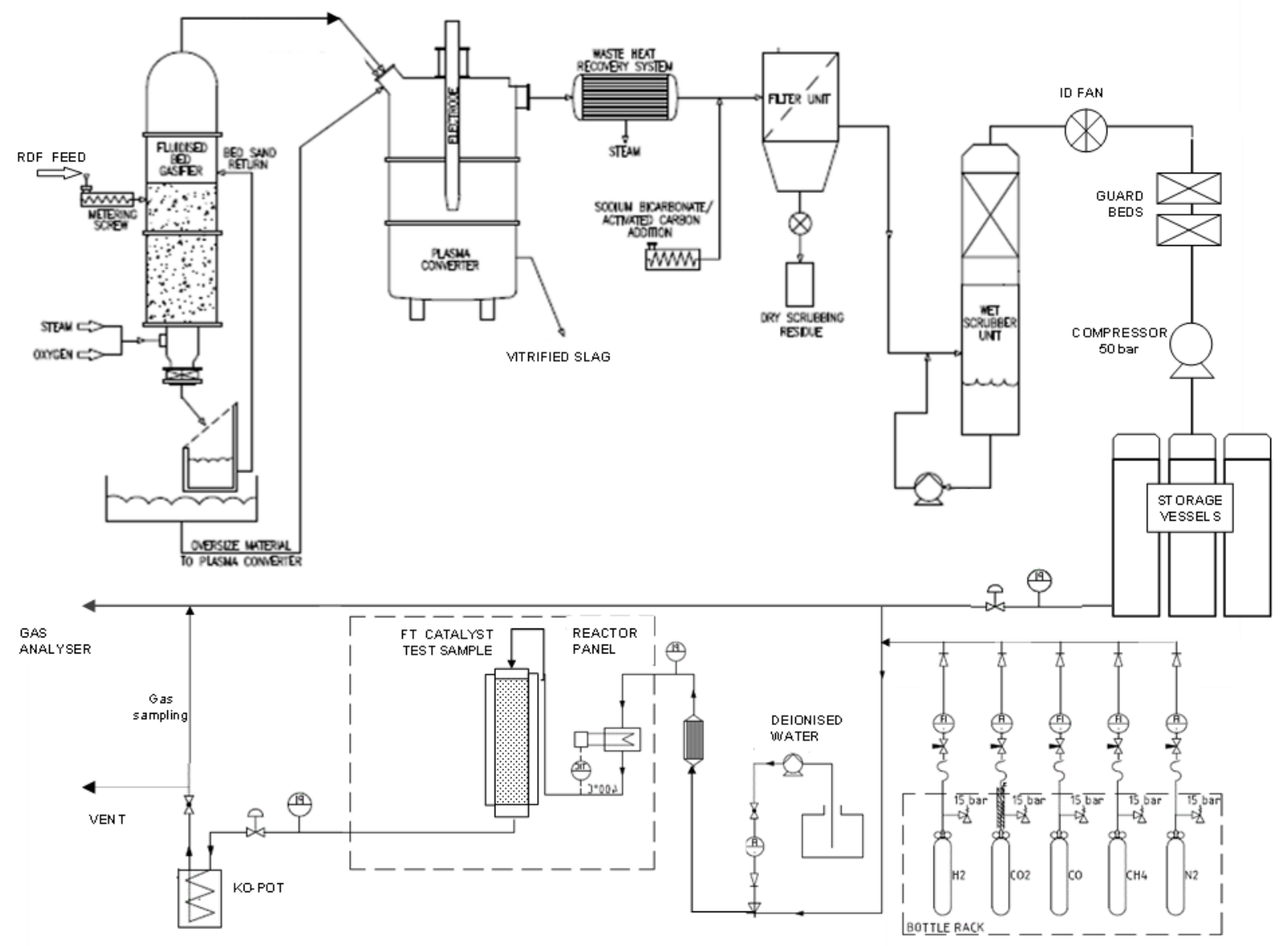

Figure 4. Schematic of the demonstration plant fror syngas generation (upper part) and small catalytic rig for catalysts testing (lower part).

\subsection{Syngas generation}

The clean syngas used for experiments is extracted from the storage vessels of a waste gasification facility in Swindon (UK) [38], briefly described in this section. From the sorting facility RDF is conveyed and metered into a bubbling fluidised bed gasifier (FBG) above a bed of coarse sand at ca. $850{ }^{\circ} \mathrm{C}$. An updraft of steam and oxygen fluidises the bed - RDF mix, whilst supporting gasification reactions. The volatile organic compounds and the fixed carbon content of the RDF are converted into a crude syngas contaminated with tarry particulates and solid chars. To overcome tar issues, the process has incorporated a second stage, with the crude syngas passing from the top of the FBG into a plasma converter (PC). Intense heat and radiation from the plasma electrode crack and reform the complex organics in the syngas - reducing tar levels drastically [37]. This is aided by a secondary oxygen and / or steam supply. At the same time, the cyclonic geometry of the PC encourages ash particulates to drop out of the syngas. Ash and inorganic material are thus retained in the molten slag, helping to avoid fouling downstream in the process. The gas cleaning includes a dry filter (ceramic filter unit with sodium bicarbonate dosing and activated carbon) followed by acid and alkaline wet scrubbers. Water condenses from the syngas as it is cooled below the dew point when entering the first scrubber. The water mixed with an acid solution dissolves almost all the nitrogenous compounds (mostly ammonia), while the alkaline 
liquor removes chloride, fluoride and Sulphur gases, as well as some of the $\mathrm{CO}_{2}$. Remaining traces of contaminants are removed in a series of activated carbon polishing units. Details of plant units are available in [37], [38], while most relevant operating parameters for syngas generation are summarized in Table 4.

The syngas used in this campaign was generated at approximately 0.05 barg pressure during three days of operation on approximately $40 \mathrm{~kg} / \mathrm{h}$ of RDF, and subsequently compressed to 50 barg through a fourstage reciprocating compressor, featuring interstage cooling with condensate removal. The compressed syngas is then extracted at the desired pressure ( $\leq 20 \mathrm{barg}$ ) and connected to the gas manifold of a fixed bed facility for catalytic screening. Differently from typical allothermal gasifiers syngas, $\mathrm{CO}_{2}$ content is higher due to the exothermic reactions in the steam-oxygen FBG. For similar reasons the hydrocarbons content is also very low. If this could appear a disadvantage from a conversion efficiency point of view (as alkanes will need to be synthesized back from the syngas), it also makes the cleaning section much easier as such syngas will be inevitably much poorer in tars, volatile organic carbons and condensable contaminants.

Table 4 Syngas specification used for baseline tests

\begin{tabular}{|c|c|c|}
\hline \multicolumn{3}{|c|}{ Process characteristics: } \\
\hline Pressure & (bar) & 1.05 \\
\hline Temperature FBG & $\left({ }^{\circ} \mathrm{C}\right)$ & $750-850$ \\
\hline Temperature PC & $\left({ }^{\circ} \mathrm{C}\right)$ & $1150-1200$ \\
\hline Oxygen & kg RDF) & 0.30 \\
\hline Steam & kg RDF) & 0.12 \\
\hline \multicolumn{2}{|c|}{ Quality Parameter: } & $\begin{array}{c}\text { Stored syngas } \\
\left(@ 50 \text { barg, } 25{ }^{\circ} \mathrm{C}\right)\end{array}$ \\
\hline $\mathrm{H}_{2}$ & vol.\% & 35.77 \\
\hline $\mathrm{CO}$ & vol. $\%$ & 33.20 \\
\hline $\mathrm{CO}_{2}$ & vol. $\%$ & 23.54 \\
\hline $\mathrm{CH}_{4}$ & vol. $\%$ & 1.67 \\
\hline $\mathrm{H}_{2} \mathrm{O}$ & vol. $\%$ & 0.89 \\
\hline $\mathrm{N}_{2}$ & vol.\% & 4.68 \\
\hline Other ( $\mathrm{Ar}, \mathrm{C}_{\mathrm{x}} \mathrm{H}_{\mathrm{y}}$, etc. $)$ & vol.\% & 0.22 \\
\hline TOTAL & vol.\% & 100.00 \\
\hline Net Calorific Value & $\mathrm{MJ} / \mathrm{kg}$ & 8.75 \\
\hline
\end{tabular}

\subsection{Synthesis reactor}

The catalytic unit used in this work is a fixed bed tubular reactor $(2.5 \mathrm{~cm} I D, 31 \mathrm{~cm}$ length) designed to be operated at a range of pressures (up to $20 \mathrm{bar}$ ) and reactor space velocities up to $10,000 \mathrm{~h}^{-1}$, taking feedstock derived from bottled gases, real syngas from the plant storage vessels, or mixtures of these. Steam can also be added by means of needle nozzle for deionised water injection in a 220-240 V tubular furnace placed before the reactor. External heating was provided to offset thermal losses in the vessel and ensure better control of the temperature during reaction and catalyst activation. Additional hydrogen was fed from a separate bottle to simulate the input from the electrolyser (referred as $\mathrm{PEM} \mathrm{H}_{2}$ ). Experiments were carried out at a constant syngas base load varying the hydrogen content to simulate fluctuating electrolysis power occurrence. Temperature was continuosly recorded in 5 locations across the length of the reactor, while gas composition was measured at the inlet of the reactor (before steam injection) and at the outlet, upon condensate removal at 1 barg and ca. $65{ }^{\circ} \mathrm{C}$ in a knock-out pot (KOP). Gas sampling lines were trace heated at $\sim 60{ }^{\circ} \mathrm{C}$ and sent to a Fourier transform infrared (FTIR) 
spectroscopy gas analyzer (Gasmet Continuous Emissions Monitoring System CEMS II-e) for online measurment. Specific gas species analyzed included: $\mathrm{CO}, \mathrm{CO}_{2}, \mathrm{H}_{2} \mathrm{O}, \mathrm{NOx}, \mathrm{SOx}, \mathrm{HF}, \mathrm{HCl}$ and a number of key LMW species (i.e. methane, ethane, ethylene, acetylene, propane, propylene, butane, iso-butane, butene, pentane, hexane, methanol, dimethylethere, benzene, toluene and naphthalene). Higher hydrocarbons, if present, would condense in the KOP before the sampling point, and residual content in the gas would therefore be very low ( $<1 \%$ vol.).

A calibration test was carried out before each trial to check whether the measured values for specific organics (mostly $\mathrm{C} 1-\mathrm{C} 4)$ were consistent with the calibration gas over a wide operating range of gas compositions. It was demonstrated that hydrocarbon levels could be recorded with an accuracy within $\pm 2 \%$ of the measured sample and there was very good consistency of measured values over a wide range of dilution.

\subsection{Catalysts screening}

The catalysts used for the series of test runs were commercially available catalysts and supplied in pellet form by Catal International Ltd (Table 5). FT1, FT2, and FT3 catalysts are typical hydrogenation catalysts based on Nickel, Iron and Cobalt respectively. The MTZ catalyst is a 50:50 wt. mix of commercial methanol production catalyst (MegaMax 800) and ZSM-5. ZSM-5 was produced from a 50 ratio $\mathrm{SiO}_{2}: \mathrm{Al}_{2} \mathrm{O}_{3}$ commercially available $\mathrm{H}^{+}$zeolite powder formed into spheres with $15 \%$ wt Alumina. As commercial catalysts have been used, a detailed characterization of the catalyst has not been carried out within the present work.

\begin{tabular}{|c|c|}
\hline $\begin{array}{l}\text { Catalyst } \\
\text { name }\end{array}$ & Catalyst composition \\
\hline FT1 & $15 \% \mathrm{Ni} / 0.5 \% \mathrm{~K} / \mathrm{Al}_{2} \mathrm{O}_{3}$ \\
\hline FT2 & $\mathrm{Fe}_{2} \mathrm{O}_{3} 92.9 \% \mathrm{SiO}_{2} 3.6 \% \mathrm{~K}_{2} \mathrm{O} \mathrm{CuO}$ \\
\hline FT3 & $20 \% \mathrm{Co}-5 \% \mathrm{Mn} / \mathrm{Al}_{2} \mathrm{O}_{3}$ \\
\hline MTZ & $20 \% \mathrm{Cu} / 55 \% \mathrm{Zn} / \mathrm{Al}_{2} \mathrm{O}_{3}: \mathrm{ZSM}-5$ (50:50 wt.) \\
\hline
\end{tabular}

Table 6 Inlet conditions for catalysts testing

\begin{tabular}{cc|c|c}
\hline \multicolumn{2}{c|}{ Inlet Conditions: } & Shifted syngas & Syngas + PEM H $\mathbf{~}_{\mathbf{2}}$ \\
\hline $\mathrm{H}_{2}$ & vol.\% & 45.0 & 61.0 \\
$\mathrm{CO}$ & vol.\% & 16.0 & 22.0 \\
$\mathrm{CO}_{2}$ & vol.\% & 35.0 & 14.0 \\
$\mathrm{~N}_{2}$ & vol.\% & 4.0 & 3.0 \\
TOTAL & vol.\% & 100 & 100 \\
Vol.flowrate & $\mathrm{Nl} / \mathrm{min}$ & 44.3 & 61.16
\end{tabular}

For the purpose of this screening test, it is determined to fix as many of the experimental factors as possible so that the evaluation of each catalyst would be under uniform conditions. The gas hourly space velocity (GHSV) is initially kept constant for each catalyst tested, at approx. $150 \mathrm{cc} / \mathrm{gm} / \mathrm{h}$. This will be done by using the same volume of each catalyst for each test while maintaining a constant gas volumetric flowrate. Only for FT1 a higher GHSV was needed to control the temperature excursion, as methanation reaction is way more exothermic than other FT pathways. Input gas stream composition is controlled to simulate the shifted product from a WGS reactor, by adding adequate quantities of $\mathrm{H}_{2}$ and $\mathrm{CO}_{2}$ to the syngas spilled from the demo plant, as reported in Table 6. The tests simulated the case in which $\mathrm{CO}_{2}$ is 
retained within the gas and not removed prior to the catalytic stage, to see whether further simplification can be implemented to the overall process layout. Furthermore, $\mathrm{H}_{2}: \mathrm{CO}$ ratio was controlled to be within 2.5 and 3 so to maximise the low molecular weight fraction of the final products. To simulate the case where Hydrogen from PEM electrolyser is made available, a pure $\mathrm{H}_{2}$ stream is added to the syngas to provide the desired $\mathrm{H}_{2}: \mathrm{CO}$ ratio, thus bypassing the WGS stage. Differently from the conventional WGS step in which the volumetric flow remains unvaried, in the latter case, the total flowrate is also increased by approximately $30 \%$ to simulate the higher gas flow caused by the occasional $\mathrm{H}_{2}$ input. Each catalyst was tested for approximately 24 hours, due to limitations in the availability of syngas from storage vessels. Operating conditions were the best available from literature or advised by catalyst supplier. Catalysts were all at similar particle size and reduced in hydrogen $\left(30 \%\right.$ vol. in $\left.\mathrm{N}_{2}, 350{ }^{\circ} \mathrm{C}\right)$ before running the tests. Depending on the specific process examined, pressure was built up to 20 bar using a back pressure regulator placed downstream the reactor. Comprehensive monitoring and control of the catalytic facility were provided via a PLC (Programmable Logic Controller)/SCADA (Supervisory Control and Data Acquisition) unit which enabled real time checking of key operating parameters, historical interrogation of data and control of key valve interlocks.

The data obtained were validated by the use of a ChemCAD stoichiometric reactor model allowing the calculation of mean values reflecting the mass and energy balance for each experiment. Performance indicating key figures such as product distribution, product selectivity and carbon monoxide conversion were calculated to determine the performance of the observed process. In particular, the product distribution was described by using the Anderson-Schultz-Flory definition:

$\log \left(W_{n} / n\right)=n^{*} \log \alpha+\log (1-\alpha)^{2} / \alpha$

where $W_{n}$ is the mass fraction of the species with carbon number $n$.

$\mathrm{C}_{\mathrm{X}}$, hydrocarbon product selectivity, $\mathrm{CO}$ conversion and LMW biofuel yields are defined respectively as:

$\mathrm{S}_{\mathrm{CX}}=\mathrm{n}_{\mathrm{CX}} /\left(\mathrm{n}_{\mathrm{CO}, \mathrm{in}}-\mathrm{n}_{\mathrm{CO}, \mathrm{out}}\right)$

Eq.12

$\mathrm{X}_{\mathrm{CO}}=1-\mathrm{n}_{\mathrm{CO}, \text { out }} / \mathrm{n}_{\mathrm{CO}, \text { in }}$

Eq.13

$\mathrm{Y}_{\mathrm{BioSNG}}=\left(\mathrm{S}_{\mathrm{C} 1}+\mathrm{S}_{\mathrm{C} 2}\right) \mathrm{X}_{\mathrm{CO}}$

Eq.14

$\mathrm{Y}_{\mathrm{BioLPG}}=\left(\mathrm{S}_{\mathrm{C} 3}+\mathrm{S}_{\mathrm{C} 4}\right) \mathrm{X}_{\mathrm{CO}}$

Eq.15

\section{RESULTS AND DISCUSSION}

A mass balance was performed over each run and the product yield results are presented in Table 7 below. The $\mathrm{CO}$ conversion, $\mathrm{CH}_{4}$ and other $\mathrm{Hcs}$ selectivities are calculated using the results obtained from the FTIR analyses. The mass of the liquid products (molecular weight higher than hexane) is assumed to be negligible at the examined conditions. The percentage of unreacted hydrogen is also calculated by difference with reference to other gas species.

One of the assumptions that were made for these calculations was that there are no product losses due to carbon deposition, and therefore all $\mathrm{C}$ products are measured by the FTIR. From experiments, carbon equilibrium was mostly achieved after few hours of continuous operation, as demonstrated by stable $\mathrm{CO}$ and $\mathrm{CO}_{2}$ content in the outlet stream. After this time, all carbon species were assumed to be recorded by the gas analyser. 


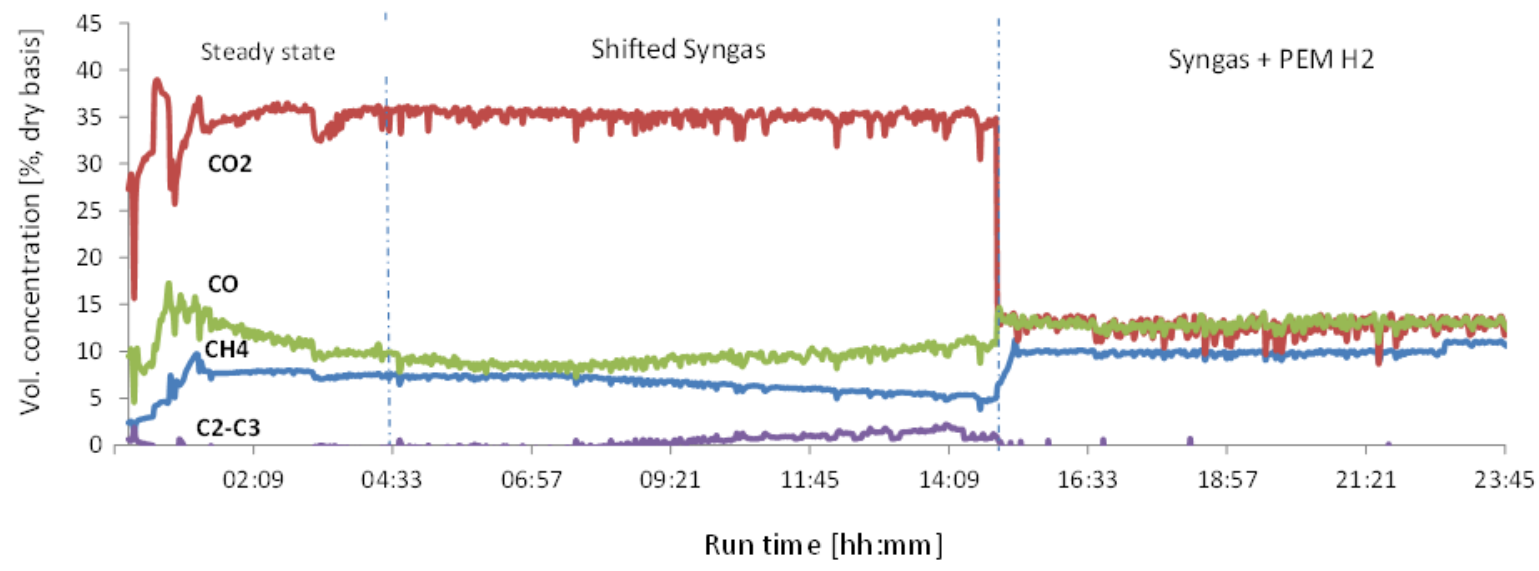

Figure 5 Experimental test for FT1 catalyst in clean syngas (no contaminants) at $300^{\circ} \mathrm{C}$ and 9 barg.

Table 7 summarises the main results of the tests. A typical trend as shown by the FTIR is presented in Figure 5 (FT1 catalyst). For the first $\sim 15$ hours of operation the system works with a mixture of waste derived syngas and $\mathrm{CO}_{2}-\mathrm{H}_{2}$ from cylinders, appropriately metered to match the "shifted syngas" composition provided in Table 6. In the second part of the experiment, pure hydrogen is mixed with the syngas to simulate the interruption of steam supply to the WGS reactor and the insertion of electrolysis $\mathrm{H}_{2}(\mathrm{PEM} \mathrm{H})$.

Table 7 Operating data on catalyst tested (baseline case). * Avg. over last hour readings and normalised.

\begin{tabular}{|c|c|c|c|c|c|c|c|c|}
\hline Catalyst & \multicolumn{2}{|c|}{ FT1 } & \multicolumn{2}{|c|}{ FT2 } & \multicolumn{2}{|c|}{ FT3 } & \multicolumn{2}{|c|}{ MTZ } \\
\hline $\begin{array}{l}\text { Avg. Temperature, }{ }^{\circ} \mathrm{C} \\
\text { Pressure, barg } \\
\text { GHSV, cc/gm/h } \\
\mathrm{H}_{2} / \mathrm{CO}\end{array}$ & \multicolumn{2}{|c|}{$\begin{array}{c}300 \\
9 \\
304.6 \\
2.81\end{array}$} & \multicolumn{2}{|c|}{$\begin{array}{c}280 \\
9 \\
152.4 \\
2.81\end{array}$} & \multicolumn{2}{|c|}{$\begin{array}{c}310 \\
9 \\
152.4 \\
2.81\end{array}$} & \multicolumn{2}{|c|}{$\begin{array}{c}320 \\
20 \\
152.4 \\
2.81\end{array}$} \\
\hline & $\begin{array}{l}\text { Shifted } \\
\text { syngas }\end{array}$ & $\begin{array}{l}\text { Syngas } \\
+\mathrm{PEMH}_{2}\end{array}$ & $\begin{array}{l}\text { Shifted } \\
\text { syngas }\end{array}$ & $\begin{array}{l}\text { Syngas } \\
+\mathrm{PEMH}_{2}\end{array}$ & $\begin{array}{l}\text { Shifted } \\
\text { syngas }\end{array}$ & $\begin{array}{l}\text { Syngas } \\
+\mathrm{PEMH}_{2}\end{array}$ & $\begin{array}{l}\text { Shifted } \\
\text { syngas }\end{array}$ & $\begin{array}{l}\text { Syngas } \\
+\mathrm{PEMH}_{2}\end{array}$ \\
\hline Alpha ( $\alpha)$ & 0.1 & 0.05 & 0.41 & 0.38 & 0.45 & 0.42 & 0.45 & 0.44 \\
\hline CO conversion, $\%$ & 18.3 & 14.3 & 50.6 & 58.9 & 36.9 & 36.8 & 15.4 & 36.4 \\
\hline $\begin{array}{l}\mathrm{CO}_{2} \text { in product, vol. } \% \\
\text { Product selectivity*, C\% }\end{array}$ & 36.0 & 9.4 & 49.3 & 24.9 & 44.1 & 18.5 & 40.0 & 19.3 \\
\hline $\begin{array}{l}\mathrm{C} 1\left(\mathrm{CH}_{4}\right) \\
\text { C2 }\left(\mathrm{C}_{2} \mathrm{H}_{6}\right) \\
\text { C2 }\left(\mathrm{C}_{2} \mathrm{H}_{4}\right) \\
\text { C3 }\left(\mathrm{C}_{3} \mathrm{H}_{8}\right) \\
\text { C3 }\left(\mathrm{C}_{3} \mathrm{H}_{6}\right) \\
\text { C4 }\left(\mathrm{C}_{4} \mathrm{H}_{8}\right) \\
\text { C4 }\left(\mathrm{I}_{2} \mathrm{C}_{4} \mathrm{H}_{8}\right) \\
\text { C5+ } \\
\text { Alcohols }\end{array}$ & $\begin{array}{c}90.5 \\
5.3 \\
1.6 \\
2.3 \\
0.2 \\
0.1 \\
0 \\
0 \\
0\end{array}$ & $\begin{array}{l}94.5 \\
3.2 \\
0.4 \\
1.8 \\
0.1 \\
0 \\
0 \\
0 \\
0\end{array}$ & $\begin{array}{c}22.8 \\
6.6 \\
15 \\
6.5 \\
18.4 \\
7.8 \\
3.1 \\
14.2 \\
5.6\end{array}$ & $\begin{array}{c}28.8 \\
9.9 \\
11.4 \\
10.2 \\
11.6 \\
10.2 \\
1.5 \\
11.6 \\
4.8\end{array}$ & $\begin{array}{c}45.1 \\
3.2 \\
5.2 \\
5.6 \\
6.1 \\
5.6 \\
2.2 \\
25.5 \\
1.5\end{array}$ & $\begin{array}{c}55.1 \\
4.2 \\
3.6 \\
3.5 \\
5.2 \\
5.2 \\
2.1 \\
19.5 \\
1.6\end{array}$ & $\begin{array}{c}8.9 \\
20.2 \\
4.6 \\
38 \\
4.1 \\
4.3 \\
12 \\
3.6 \\
4.3\end{array}$ & $\begin{array}{c}6.8 \\
24.8 \\
4.2 \\
40 \\
2.8 \\
11.2 \\
5.3 \\
1.6 \\
3.3\end{array}$ \\
\hline $\begin{array}{l}\text { Paraffin/Olefin } \\
\text { LMW biofuel yield, mol.\% }\end{array}$ & +++ & +++ & + & + & + & ++ & ++ & ++ \\
\hline BioSNG & 17.6 & 14.7 & 19.3 & 26.3 & 17.9 & 22.1 & 4.9 & 12.3 \\
\hline BioLPG & 0.5 & 0.3 & 15.5 & 17.6 & 6.5 & 5.6 & 8.5 & 20.4 \\
\hline Others (bionaphtha, etc.) & 0.0 & 0.0 & 6.2 & 6.1 & 8.6 & 6.9 & 0.5 & 0.6 \\
\hline
\end{tabular}




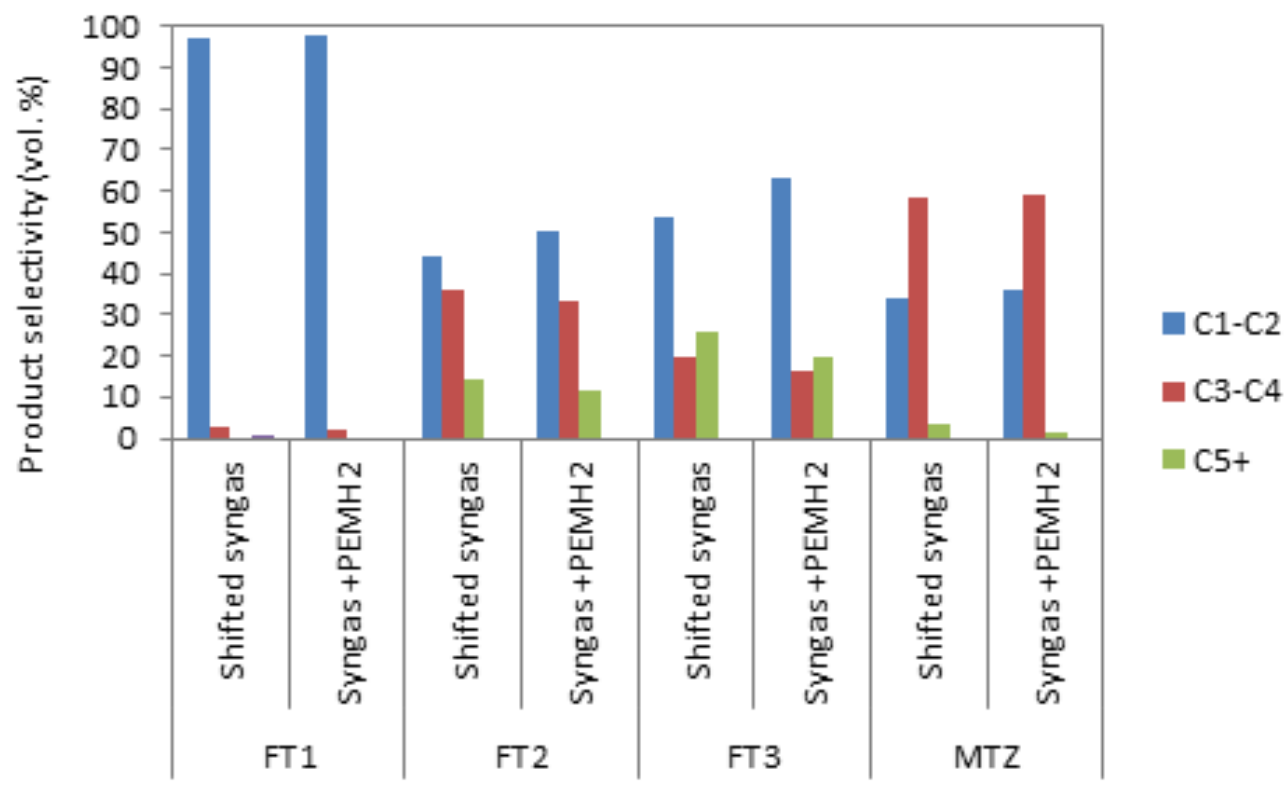

Figure 6 Light hydrocarbons distribution for the 4 catalysts tested

\subsection{Shifted syngas (baseline case)}

Referring to Table 7, all catalysts turned out to be active in converting syngas to LMW hydrocarbons. Catalyst FT1 is a supported nickel catalyst, which is well known to be an excellent methanation catalyst. Compared to more typical FT catalysts, Ni proved to very active at $300{ }^{\circ} \mathrm{C}$ and low space velocity, thus making the control of the reactor temperature more challenging. Accordingly, the system was tuned to stay over approx. $18 \%$ conversion, in line with that achieved previously with a $15 \% \mathrm{Ni} / \mathrm{Al}_{2} \mathrm{O}_{3}$ methanation catalyst [38]. $\mathrm{CO}_{2}$ formation also indicates strong carbon deposition tendency when running at zero steam-to-gas ratios, as in this case. Partly supporting this evidence, CO conversion steadily decreased with time after the first 7 hours of operation, but it was impossible to determine whether this is due to the carbon deposition issue mentioned above, or to any other reason associated to syngas composition. The former is expected to be the most likely cause as when higher $\mathrm{H}_{2} /\left(\mathrm{CO}+\mathrm{CO}_{2}\right)$ ratio was used (syngas + $P E M \mathrm{H}_{2}$ ), higher and steady activity was restored, and mantained so until the end of the trial. In both feed gas cases the amount of $\mathrm{CO}$ converted to olefins and hydrocarbons higher than propane was negligible, whilst methane was more than $90 \%$ of the hydrocarbon product (Figure 6), making this catalyst particularly ideal for bioSNG production. In this specific case, bioSNG yield is limited by the reduced CO conversion imposed by the experimental system. Given the high selectivity and reaction rate of Nickel catalysts, bioSNG yields of up to $90 \%$ can be expected in industrial systems, as demonstrated by existing SNG plants [74].

Iron catalyst (FT2) is very active for the reaction with $\mathrm{CO}$ and $\mathrm{CO}_{2}$ at the conditions chosen, with $\mathrm{CO}$ conversion steadily increasing over time, until peaking $50 \%$ after $\sim 15$ hours of operation. One of the reason could be the high $\mathrm{CO}$ and $\mathrm{CO}_{2}$ partial pressure at the initial conditions, which favour the catalitically active carbide formation. Further activation of the FT2 catalyst could be achieved if $\mathrm{CO}$ or syngas were used as reducing agents [75]. This catalyst gives low methane production relative to $\mathrm{C2}-\mathrm{C} 4$. The amount of $\mathrm{CO}$ converted to $\mathrm{C} 5+$ is also modest for a typical FT catalyst as is the production of alcohols. The iron catalyst gave also the highest $\mathrm{CO}_{2}$ yields amongst $\mathrm{FT}$ examples. This was expected since iron is known to be a good catalyst for the water gas shift reaction. Differently from that of Nickel, Iron based FT catalysts activity develops slowly after several hours on stream and attains steady state in several days. This phenomenon is called "self-organizazion" of the catalyst, and is controlled by the progressive Fe-carbide 
and carbon phases formation [76]. For this reason, it is difficult to ascertain FT2 catalyst activity in short runs, and observation made in this work can only be partially validated with the established FT literature. Nevertheless, results were reasonably in line with other works on similar catalysts composition and process conditions [75], [77].

Catalyst FT3 had a lower activity compared with Iron but could be brought up to appreciable activity by raising the temperature to $310{ }^{\circ} \mathrm{C}$. At these conditions the catalyst showed high methane and $\mathrm{C} 5+$ production (selectivity of 22.8 and 14.2, respectively) with very low alcohols formation. Still the activity for C2-C4 production was considerable and these products were better than $40 \%$ unsaturated, in both inlet syngas cases. These results confirmed the highest hydrogenation capacity of Cobalt when compared to Iron, as also reported elsewhere [75], [76].

The largest fraction of C2-C4 hydrocarbons and bioLPG yield were produced with MTZ composite catalyst. This narrow distribution is a clear indication of the shape selectivity of the zeolite component of the catalyst. Methanol was also detected in the product, although in small quantity, due to the effect of the zeolite in converting methanol to hydrocarbons in the $\mathrm{C} 1-\mathrm{C} 4$ range. The large amount of paraffinic hydrocarbons was due to hydrogenation of olefins, also in line with results from other researchers [78]. Compared to similar studies at similar operating conditions, overall CO conversion was rather limited $(\sim$ $15.4 \%)$, this affecting also overall LMW biofuel yields. This might be due to the presence of high quantities of $\mathrm{CO}_{2}$ in the syngas, which inhibit $\mathrm{CO}$ conversion to hydrocarbons [79]. When the feed gas had no or low $\mathrm{CO}_{2}$ content, $\mathrm{CO}$ conversions of up to $80 \%$ have been reported [70], thus raising bioLPG yield to above $40 \%$.

\subsection{Syngas - $P E M \mathrm{H}_{2}$ case}

The addition of hydrogen to the syngas mixture to simulate the connection with the electrolyser has a twofold function on the catalytic system. On one side it increases the $\mathrm{H}_{2}$ :Carbon ratio with relation to both $\mathrm{CO}$ and $\mathrm{CO}_{2}$, on the other it increases the volumetric gas flow, thus the resulting space velocity in the fixed bed. As such, different effects are to be expected. The hydrogen addition has a rather drastic effect in the paraffin selectivity, but a lower effect on the alpha value, as shown in Figure 5 . An increase in the $\mathrm{H}_{2}$ :COx ratio strongly increases the reaction rate, as well as the paraffin selectivity. This will be a function of an increase in hydrogen surface coverage and the positive equilibrium effects that increases in $\mathrm{H}_{2}$ partial pressure have on the $\mathrm{FT}$ reaction which are known to cause higher methane and paraffins production [63], [64]. In addition, an increasing $\mathrm{H}_{2}: \mathrm{CO}$ molar ratio has been reported to improve the exothermic heat removal in the reactor and enhance the catalyst life and activity as carburisation (or coke formation) on the catalyst surface is minimized [80]. This was reflected by a continuous and steady CO conversion over the second half of the trials, as shown in Figure 5.

Values in Table 7 show also that increasing hydrogen content, CO conversion increases, C1-C4+ paraffin selectivity increases and, overall, the LMW hydrocarbon productivity increased. It is difficult to say, however, if these were the effects of an increase in $\mathrm{H}_{2}: \mathrm{COx}$, or of an increase of the space velocity due to higher gas flow, or both. These results demonstrated that the relationship that exists between inlet conditions and product distribution is not straight forward and may be unique for specific reactor systems, catalysts and reaction conditions, as confirmed by many studies [77], [81], [82].

Finally, it was observed that in all cases, the catalytic activities (i.e carbon conversions) with lower $\mathrm{CO}_{2}$ content (as in the PEM H $\mathrm{H}_{2}$ case) were higher than those obtained with shifted gas composition. Several authors [81] agree that this decrease could be attributed to the oxidizing character of $\mathrm{CO}_{2}$ that would lead to the oxidation of metal particles present on the support, negatively affecting to the catalyst performance. Also, $\mathrm{CO}_{2}$ is a more stable molecule and thermodynamically less active for hydrogenation than is $\mathrm{CO}$. These results could also be a consequence of the possible competition between $\mathrm{CO}_{2}$ and $\mathrm{CO}$ for the adsorption sites of the catalyst. This suggests that $\mathrm{CO}_{2}$ would be better removed before the catalytic stages and reacted separately with excess $\mathrm{H}_{2}$, should this be available. In the first case only (FT1), $\mathrm{CO}_{2}$ 
seems to behave as an inert gas, at least until most of the $\mathrm{CO}$ is consumed by the methanation reaction. This leads to the conclusion that the production of bioSNG supported by fluctuating wind energy can be realized without the need of a $\mathrm{CO}_{2}$ removal and gas (either $\mathrm{CO}_{2}$ or $\mathrm{H}_{2}$ ) storage upstream the methanation stage. On periods when surplus electricty is available, the plant can automatically accept additional hydrogen to produce more methane from hydrogenation of $\mathrm{CO}_{2}$ in the syngas, as shown in next section. Any other time in which external $\mathrm{H}_{2}$ is not available, $\mathrm{CO}_{2}$ acts as inert, and is conveniently removed from the gas product at the end.

\subsection{Overall process overview}

The experimental campaign has proved that significant amounts of low molecular weight biofuel can be produced by controlling the operating conditions, and hydrogen partial pressures, in the catalytic transformation of clean waste derived syngas. Due to the reduced scale and discontinued operation, the campaign had a number of inherent inefficiencies, and direct projections can only partly be made. Research demanded catalytic experiments to be undertaken in a single stage fixed bed process and limited time, which resulted in reduced $\mathrm{CO}$ conversions. Product distribution might be affected by conversion, as reported by several authors [83]; as such, catalysts must be tested at a higher CO conversions to further validate this study. More than 100 years of commercial fuel synthesis catalysis have proved that many strategies could be adopted to achieve near complete syngas conversion, including feed gas staging, water removal, and multi-step reactors. Product recycling is also very effective in getting higher conversion, but it is best avoided in WtG plants for the reasons mentioned in Section 2.5. In this sense, the trade off in lower CO conversions and once-through LMW biofuel product yields has to be carefully weighed against the potential cost savings resulting from a simplified process scheme. Preliminary results from Section 4,1 have shown that externally produced hydrogen could also help achieving better performance in a once-through process.

To better illustrate the difference in performance of the two operational routes (i.e. with and without external $\mathrm{H}_{2}$ addition), a full scale projection is made for the FT1 case, for which more exhaustive data were available from the pilot plant [31], [38] and the literature [84], [85]. A representative Mass and Energy balance for a plant treating 113,000 tpa of MSW (corresponding to approximately $65 \mathrm{MW}$ of RDF thermal input) to produce a range of $\mathrm{C} 1-\mathrm{C} 2$ hydrocarbons (marketable as bioSNG) for the two cases, is presented in Table 8. The predominate energy inputs to the process are the RDF feedstock, the electricity consumption associated to plasma converter, ASU, electrolyser, and major utilities (e.g. ID fan, compressors, electric heaters, etc.). For the integrated WtG case, two different capacity factors are considered, namely 40 and $100 \mathrm{MW}$ of electrical input from renewable sources. These correspond approximately to the average amount of excess power that a typical stationary $200 \mathrm{MW}$ wind or solar farm could produce (assuming the average load demand is $\sim 100-150 \mathrm{MW}$ ). Systems meeting most or all their power demand with wind and solar could use WtG to store the excesses and using at least some portion of them to meet the shortfalls. Predominate energy outputs are the final products and various thermal losses. Steam and heat generated were assumed to be used internally and not considered, for example, for further electricity production. This allows for a more conservative estimation to be provided. 
Table 8 Performance analysis of a $65 \mathrm{MW}$ WtG (bioSNG) plant

\begin{tabular}{|c|c|c|c|c|c|}
\hline Parameter: & $\begin{array}{l}\text { Calculation } \\
\text { Basis }\end{array}$ & Units & $\begin{array}{c}\text { Baseline } \\
\text { case }\end{array}$ & \multicolumn{2}{|c|}{ PEM $\mathrm{H}_{2}$ Integrated case } \\
\hline Raw waste input & & tpa & 113,385 & \multicolumn{2}{|c|}{113,385} \\
\hline \multirow[t]{2}{*}{ Prepared RDF } & & tpa & 92,060 & \multicolumn{2}{|c|}{92,060} \\
\hline & {$[\mathrm{A}]$} & MW & 65 & \multicolumn{2}{|c|}{65} \\
\hline Oxygen input & & tpa & 30,700 & \multicolumn{2}{|c|}{30,700} \\
\hline ASU & [B] & MW & 1.6 & \multicolumn{2}{|c|}{0.0} \\
\hline Vitrified ash & & tpa & 14,066 & \multicolumn{2}{|c|}{14,066} \\
\hline $\begin{array}{l}\text { Other energy input } \\
\text { (PC, compressors, etc.) }\end{array}$ & {$[\mathrm{C}]$} & MW & 6.7 & \multicolumn{2}{|c|}{6.7} \\
\hline PEM & [D] & MW & 0.0 & 40 & 100 \\
\hline \multicolumn{6}{|l|}{ Products: } \\
\hline \multirow[t]{2}{*}{ BioSNG } & {$[E]$} & MW & 39.0 & 57.8 & 92.9 \\
\hline & & tpa & 18,850 & 27,900 & 44,920 \\
\hline \multirow[t]{2}{*}{$\mathrm{RenH}_{2}$} & {$[\mathrm{~F}]$} & MW & 0.5 & 0.4 & 4.6 \\
\hline & & tpa & 90.5 & 75.5 & 872.7 \\
\hline $\mathrm{CO}_{2}$ & & tpa & 109,455 & 62,600 & 37,900 \\
\hline $\begin{array}{l}\text { Waste conversion } \\
\text { efficiency } \\
\text { (WCE) }\end{array}$ & $\begin{array}{l}{[H]=} \\
([F]+[E]) /[A]\end{array}$ & $\%$ & $62.31 \%$ & $89.54 \%$ & $150.00 \%$ \\
\hline $\begin{array}{l}\text { Net energy efficiency } \\
\text { (NEE) }\end{array}$ & $\begin{array}{l}\text { [J] = } \\
([\mathrm{F}]+[\mathrm{E}]) / \\
([\mathrm{A}]+[\mathrm{B}]+[\mathrm{C}]+[\mathrm{D}])\end{array}$ & $\%$ & $56.80 \%$ & $53.30 \%$ & $57.45 \%$ \\
\hline
\end{tabular}

It is seen that for the baseline process, waste conversion efficiency of above $62 \%$ is attained which compares well with published efficiencies for bioSNG from biomass plants of $60 \%$ [86]. Furthermore, when account is made of the parasitic load then, despite the use of an air separation unit and a plasma arc to vitrify ash and crack residual tars and condensable organics, the process reports a net energy efficiency (NEE) of around $57 \%$.

Although large part of the carbon within RDF is recovered in the bioSNG product, still almost 110,000 tonnes of $\mathrm{CO}_{2}$ are produced each year in the reference case. Overall, bioSNG is reported to produce significantly lower carbon emissions when compared to the full life cycle of natural gas [87]. However, these could be dramatically reduced if additional hydrogen from a connected PEM is made available. For example, if $40 \mathrm{MW}$ of electrical output from renewable sources are used to power a PEM stack during low demand time, the production of bioSNG could be increased by approximately $33 \%$, with a simultaneous reduction in $\mathrm{CO}_{2}$ emissions of more than $43 \%$ (i.e. 62,600 tpa). Furthermore, despite the use of high value electricity to boost the performance of the plant, the NEE is only minimally affected. This is due to the fact that the energy expenditure is almost completely offset by the enhanced biofuel production, and reduced parasitic loads associated to oxygen production. This compensating effect is even more evident if higher fraction of renewable power is available. In the $100 \mathrm{MW}$ PEM case, the energy content of the fuel product is equal to the $150 \%$ of the original energy value in waste, with a resulting NEE even higher than the original baseline value. Figure 7 shows clearly the effect of additional renewable power integrated in the $\mathrm{WtG}$ process on the final product gas and $\mathrm{CO}_{2}$ yields, which gives 
nearly specular trends, i.e. with increasing the fraction of renewable power available, more bioSNG is produced at the expense of $\mathrm{CO}_{2}$. Bio-hydrogen is also expected to be increasing in the final product as more is fed into the system, although to a much lower extent.

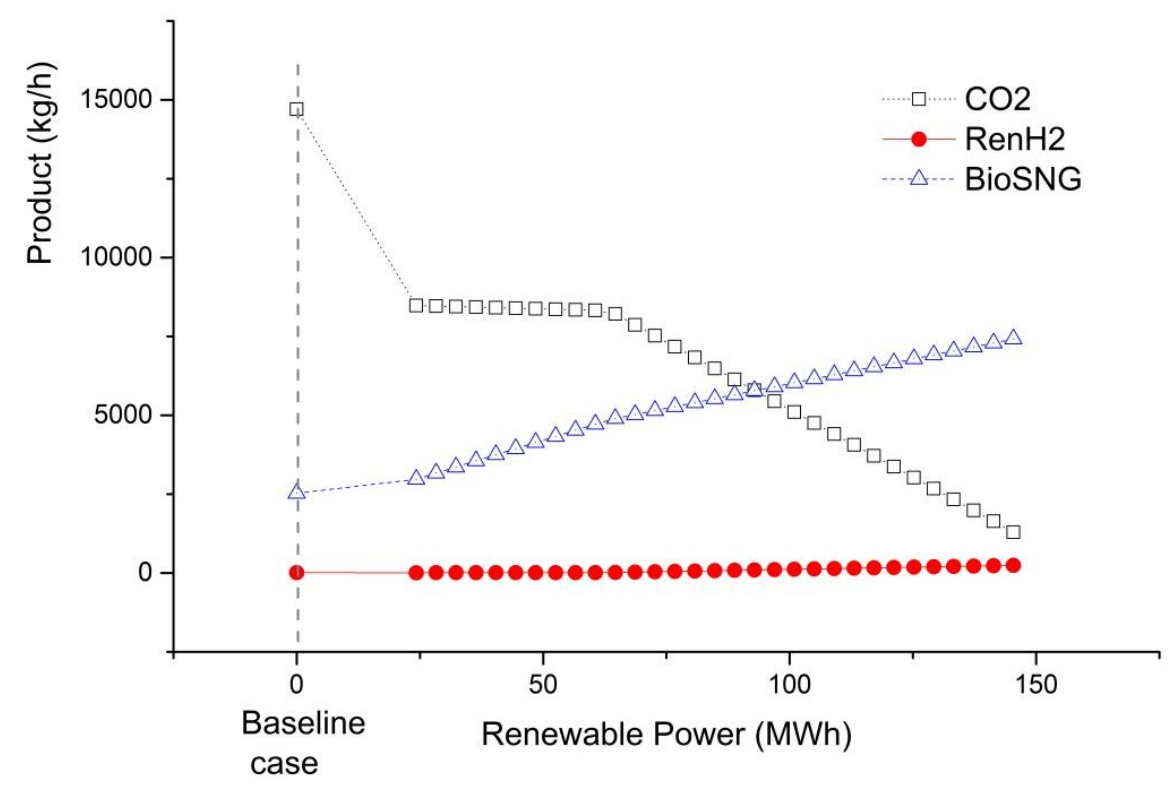

Figure 7 Effect of renewable power integration into a WtG process (65 MW) in terms of final products formation

Similarly, waste conversion efficiency increases almost linearly with electric power while NEE remain almost constant (Figure 8). Similar findings have been presented by other authors in different biomass to fuel applications when additional hydrogen is added to the syngas [62], [88].

In theory, this advantageous relation would be valid until all or most of the $\mathrm{CO}_{2}$ within the syngas is converted to LMW hydrocarbons. In reality, there are technical and commercial constraints which would limit the benefits beyond a certain point. In this specific bioSNG case, for example, hydrogen in the product is normally limited to few percent of the total volume to meet the Gas Safety Management Regulation (GSMR) for injection into the national grid. Depending on local legislation, a derogation to introduce gas with higher levels of hydrogen (up to $10-20 \%$ vol.), would avoid the need of costly gas separation units [38]. Finally, the continuous, dynamic operation of PEM electrolysers has only been proven at moderate scale ( $<100 \mathrm{MW}$ electrical input), and further work is needed to make them efficient and economically viable for larger applications. 


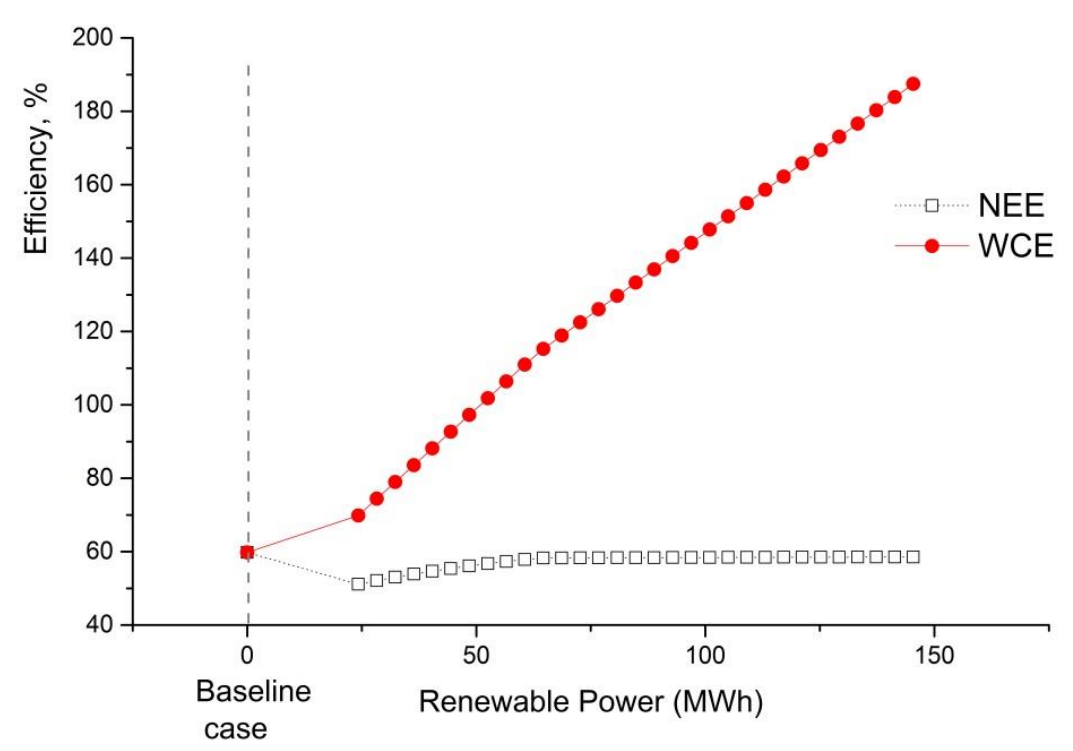

Figure 8 Effect of renewable power integration on waste conversion (WCE) and net energy efficiencies (NEE) of a WtG process (65 MW).

\section{CONCLUSIONS}

This work investigates the possibilities for the specific production of LMW hydrocarbon products utilising a good quality syngas produced by waste gasification. The potential benefits of introducing renewable power to the Waste-to-Gas process are also explored. A number of catalysts were prepared and tested on bottled and real waste derived syngas. The catalysts selected were relatively simple and commercially available materials to selectively convert synthesis gas, derived from waste, to low molecular weight hydrocarbons in the range of $\mathrm{C} 1$ to $\mathrm{C} 4$. The main observations drawn from this study are:

- The objective of LMW gaseous products requires the absence of air nitrogen in the syngas, in order to lower cost of upgrading at the reduced scale demanded by waste operation. This is achievable by using indirect gasification or steam/oxygen fluidised beds.

- The combination of an oxy-steam fluidised bed gasifier directly coupled to tar cracking plasma unit delivers a high quality syngas from RDF produced from municipal solid waste. The simplified downstream gas processing and polishing techniques have been shown to provide syngas of sufficient quality for catalyst operation, even at a reduced scale.

- The provision of external hydrogen is effective in adjusting the $\mathrm{H}_{2}: \mathrm{CO}$ ratio to values suitable for hydrogenation reactions, without producing additional $\mathrm{CO}_{2}$ as normally occurs within the water gas shift step.

- Satisfactory LMW hydrocarbon selectivities from waste derived syngas could be obtained by operating FT and $\mathrm{MtH}$ catalysts at high temperatures and sustained gas velocity. $\mathrm{H}_{2}: \mathrm{CO}$ ratio higher than 2 is needed to enhance productions of shorter hydrocarbon chains and paraffinic fractions. LMW biofuel yields vary between 15 and $45 \%$ at the conditions examined.

- The retention of $\mathrm{CO}_{2}$ within the reacting syngas is only beneficial to methanation, and to a lower extent, Methanol-to-Hydrocarbons reactions. In all other cases, $\mathrm{CO}_{2}$ is better removed before the catalytic stages and reacted separately with renewable $\mathrm{H}_{2}$, should this be available.

- When increasing $\mathrm{H}_{2}$ : $\mathrm{CO}$ in the syngas by external addition of hydrogen, $\mathrm{CO}$ conversion increases, C1-C4 paraffin selectivity increases and, overall, the LMW hydrocarbon productivity increased remarkably. 
- Projections on a $65 \mathrm{MW}$ thermal input bioSNG plant show that if $40 \mathrm{MW}$ of electrical output from renewable sources are used to power a PEM stack during low demand time, the production of bioSNG could be increased by more than $33 \%$, with a simultaneous reduction in $\mathrm{CO}_{2}$ emissions of more than $43 \%$. Furthermore, despite the use of high value electricity to boost the performance of the plant, the NEE is only minimally affected. This is due to the fact that the energy expenditure is almost completely offset by the enhanced biofuel production, and reduced parasitic loads associated to oxygen production. This compensating effect is even more evident if a higher fraction of renewable power is available.

Although most of the elements of the examined $\mathrm{WtG}$ process are mature and proven technologies at reduced scale (up to few $\mathrm{MW}$ ), more research and sustained operation is needed to improve flexibility, reliability and effective scalability. In particular, future campaign should focus on prolonged operation of a fully integrated plant, process optimization for each specific catalytic route, and economic analysis to assess process viability. The results of these campaigns are expected to be an important component to enable future deployment of Waste-to-Gas plants.

\section{AKNOWLEDGEMENTS}

The author wishes to acknowledge Advanced Plasma Power Ltd and Dr. Richard Taylor for the support provided through the experimental phase. Financial support from the Royal Academy of Engineering (RAEng) is also acknowledged.

\section{REFERENCES}

[1] H. W. Schiffer, "WEC energy policy scenarios to 2050," Energy Policy, vol. 36, no. 7, pp. 2464-2470, 2008.

[2] T. Trainer, Renewable energy cannot sustain a consumer society. 2007.

[3] C. Mao, Y. Feng, X. Wang, and G. Ren, "Review on research achievements of biogas from anaerobic digestion," Renewable and Sustainable Energy Reviews, vol. 45. pp. 540-555, 2015.

[4] B. Drosg, R. Braun, G. Bochmann, and T. Al Saedi, "Analysis and characterisation of biogas feedstocks," in The Biogas Handbook: Science, Production and Applications, 2013.

[5] L. Yang, X. Ge, C. Wan, F. Yu, and Y. Li, "Progress and perspectives in converting biogas to transportation fuels," Renewable and Sustainable Energy Reviews, vol. 40. pp. 1133-1152, 2014.

[6] J. J. Cheng and G. R. Timilsina, "Status and barriers of advanced biofuel technologies: A review," Renew. Energy, 2011.

[7] A. Demirbaş, "Bioethanol from cellulosic materials: A renewable motor fuel from biomass," Energy Sources, 2005.

[8] H. H. Khoo, "Review of bio-conversion pathways of lignocellulose-to-ethanol: Sustainability assessment based on land footprint projections," Renewable and Sustainable Energy Reviews. 2015.

[9] W. Ahmed and B. Sarkar, "Impact of carbon emissions in a sustainable supply chain management for a second generation biofuel," J. Clean. Prod., 2018.

[10] T. Kalnes, T. Marker, and D. R. Shonnard, "Green Diesel: A Second Generation Biofuel," Int. J. Chem. React. Eng., 2007.

[11] V. Balan, "Current Challenges in Commercially Producing Biofuels from Lignocellulosic Biomass," ISRN Biotechnol., 2014.

[12] S. K. Hoekman, A. Broch, C. Robbins, E. Ceniceros, and M. Natarajan, "Review of biodiesel composition, properties, and specifications," Renewable and Sustainable Energy Reviews. 2012.

[13] S. Bezergianni and A. Dimitriadis, "Comparison between different types of renewable diesel," Renewable and Sustainable Energy Reviews. 2013.

[14] A. I. BAMGBOYE and A. C. HANSEN, "Prediction of cetane number of biodiesel fuel from the fatty acid methyl ester (FAME) composition," Int. agrophysics, 2008.

[15] D. Kubička, J. Chudoba, and P. Šimáček, "Catalytic conversion of vegetable oils into transportation fuels," in DGMK Tagungsbericht, 2008. 
[16] Y. K. Oh, K. R. Hwang, C. Kim, J. R. Kim, and J. S. Lee, "Recent developments and key barriers to advanced biofuels: A short review," Bioresource Technology. 2018.

[17] T. H. Leena Rantanen, Raimo Linnaila, Päivi Aakko, "NExBTL - second generation renewable diesel," SAE Tech. Pap. 2005-01-3771, 2005.

[18] T. P. T. Pham, R. Kaushik, G. K. Parshetti, R. Mahmood, and R. Balasubramanian, "Food waste-toenergy conversion technologies: Current status and future directions," Waste Management. 2015.

[19] EEA(2017), "Municipal waste management across European countries," Eur. Environ. Agency, 2017.

[20] P. Lettieri, L. Yassin, and S. J. R. Simons, "Advanced thermal treatment of composite wastes for energy recovery," in Management, Recycling and Reuse of Waste Composites, 2009.

[21] A. N. Stranges, "A history of the fischer-tropsch synthesis in Germany 1926-45," in Studies in Surface Science and Catalysis, 2007.

[22] M. Iglesias Gonzalez, B. Kraushaar-Czarnetzki, and G. Schaub, "Process comparison of biomass-toliquid (BtL) routes Fischer-Tropsch synthesis and methanol to gasoline," Biomass Convers. Biorefinery, 2011.

[23] S. S. Ail and S. Dasappa, "Biomass to liquid transportation fuel via Fischer Tropsch synthesis Technology review and current scenario," Renewable and Sustainable Energy Reviews. 2016.

[24] J. Hu, F. Yu, and Y. Lu, "Application of Fischer-Tropsch Synthesis in Biomass to Liquid Conversion," Catalysts, 2012.

[25] a Oasmaa, D. C. Elliott, and S. Mu, "Quality Control in Fast Pyrolysis Bio-Oil Production and Use," Environ. Prog., vol. 28, no. 3, pp. 404-409, 2009.

[26] M. F. Demirbas and M. Balat, "Recent advances on the production and utilization trends of bio-fuels: A global perspective," Energy Convers. Manag., 2006.

[27] D. C. Elliott, P. Biller, A. B. Ross, A. J. Schmidt, and S. B. Jones, "Hydrothermal liquefaction of biomass: Developments from batch to continuous process," Bioresour. Technol., vol. 178, pp. 147-156, Oct. 2014.

[28] F. J. Keil, "Methanol-to-hydrocarbons: Process technology," Microporous and Mesoporous Materials. 1999.

[29] H. M. Torres Galvis and K. P. De Jong, "Catalysts for production of lower olefins from synthesis gas: A review," ACS Catalysis. 2013.

[30] M. Stöcker, "Methanol to Olefins (MTO) and Methanol to Gasoline (MTG)," in Zeolites and Catalysis: Synthesis, Reactions and Applications, 2010.

[31] M. Materazzi, F. Grimaldi, P. U. Foscolo, P. Cozens, R. Taylor, and C. Chapman, "Analysis of syngas methanation for bio-SNG production from wastes: kinetic model development and pilot scale validation," Fuel Process. Technol., vol. 167, 2017.

[32] D. C. Lynch, "Enerkem renewable chemicals and biofuels for sustainable communities," in International Conference on Thermal Treatment Technologies and Hazardous Waste Combustors 2014, 2014.

[33] S. Sunderasan, "GoBiGas: Fueling the Biogas Movement," in Cleaner-Energy Investments, 2014.

[34] R. Tichler and S. Bauer, "Power-to-Gas," in Storing Energy: With Special Reference to Renewable Energy Sources, 2016, pp. 373-389.

[35] a. . Bridgwater, "Renewable fuels and chemicals by thermal processing of biomass," Chem. Eng. J., vol. 91, no. 2-3, pp. 87-102, 2003.

[36] M. Materazzi and P. Lettieri, "Fluidized Beds for the Thermochemical Processing of Waste," in Reference Module in Chemistry, Molecular Sciences and Chemical Engineering, Elsevier, 2017.

[37] M. Materazzi, P. Lettieri, L. Mazzei, R. Taylor, and C. Chapman, "Tar evolution in a two stage fluid bedplasma gasification process for waste valorization," Fuel Process. Technol., vol. 128, 2014.

[38] M. Materazzi, R. Taylor, P. Cozens, and C. Manson-Whitton, "Production of BioSNG from waste derived syngas: Pilot plant operation and preliminary assessment," Waste Manag., vol. 79, pp. 752-762, 2018.

[39] M. Materazzi and P. Lettieri, "Fluidized Beds for the Thermochemical Processing of Waste," in Reference Module in Chemistry, Molecular Sciences and Chemical Engineering, 2017.

[40] U. Arena and M. L. Mastellone, "Pyrolysis and gasification of solid wastes in fluidized-bed reactors," IFSA, 2005.

[41] J. Konttinen, R. Backman, M. Hupa, A. Moilanen, and E. Kurkela, "Trace element behavior in the fluidized bed gasification of solid recovered fuels - A thermodynamic study," Fuel, vol. 106, pp. 621631, 2013.

[42] U. Arena, L. Zaccariello, and M. L. Mastellone, "Fluidized bed gasification of waste-derived fuels," Waste Manag., vol. 30, no. 7, pp. 1212-1219, 2010.

[43] V. Wilk and H. Hofbauer, "Conversion of mixed plastic wastes in a dual fluidized bed steam gasifier," Fuel, vol. 107, 2013.

[44] U. Arena and F. Di Gregorio, "Energy generation by air gasification of two industrial plastic wastes ina 
pilot scale fluidized bed reactor, Earcía-lbañez, A. Cabanillas, and J. M. Sánchez, "Gasification of leached orujillo (olive oil waste) in a pilot plant circulating fluidised bed reactor. Preliminary results," Biomass and Bioenergy, 2004.

[46] V. Wilk, H. Kitzler, S. Koppatz, C. Pfeifer, and H. Hofbauer, "Gasification of waste wood and bark in a dual fluidized bed steam gasifier," Biomass Convers. Biorefinery, 2011.

[47] E. Kurkela, M. Kurkela, and I. Hiltunen, "Steam-oxygen gasification of forest residues and bark followed by hot gas filtration and catalytic reforming of tars: Results of an extended time test," Fuel Process. Technol., vol. 141, pp. 148-158, 2016.

[48] U. Arena, "17 - Fluidized bed gasification," in Fluidized Bed Technologies for Near-Zero Emission Combustion and Gasification, F. Scala, Ed. Woodhead Publishing, 2013, pp. 765-812.

[49] A. Leclerc and F. Larachi, "Allothermal fluidized bed reactor for steam gasification of biomass," Instrum. Sci. Technol., 2015.

[50] M. Materazzi, P. Lettieri, R. Taylor, and C. Chapman, "Performance analysis of RDF gasification in a two stage fluidized bed-plasma process," Waste Manag., vol. 47, 2016.

[51] Y. Byun et al., "Demonstration of thermal plasma gasification/vitrification for municipal solid waste treatment.," Environ. Sci. Technol., vol. 44, no. 17, pp. 6680-6684, 2010.

[52] Q. Wang et al., "Thermal treatment of municipal solid waste incinerator fly ash using DC double arc argon plasma," Fuel, 2009.

[53] E. Gomez, D. A. Rani, C. R. Cheeseman, D. Deegan, M. Wise, and A. R. Boccaccini, "Thermal plasma technology for the treatment of wastes: A critical review," Journal of Hazardous Materials, vol. 161, no. 2-3. pp. 614-626, 2009.

[54] M. Siedlecki and W. de Jong, "Biomass gasification as the first hot step in clean syngas production process - gas quality optimization and primary tar reduction measures in a $100 \mathrm{~kW}$ thermal input steamoxygen blown CFB gasifier," Biomass and Bioenergy, vol. 35, no. SUPPL. 1, pp. S40-S62, 2011.

[55] C. H. Bartholomew, "Mechanism of catalyst deactivation.," Appl. Catal. A Gen., vol. 212, pp. 17-60, 2001.

[56] N. Abdoulmoumine, S. Adhikari, A. Kulkarni, and S. Chattanathan, "A review on biomass gasification syngas cleanup," Applied Energy. 2015.

[57] M. Asadullah, "Biomass gasification gas cleaning for downstream applications: A comparative critical review," Renewable and Sustainable Energy Reviews. 2014.

[58] P. J. Woolcock and R. C. Brown, "A review of cleaning technologies for biomass-derived syngas," Biomass and Bioenergy. 2013.

[59] M. Götz et al., "Renewable Power-to-Gas: A technological and economic review," Renewable Energy, vol. 85. pp. 1371-1390, 2016.

[60] J. Agerborg and E. Lingehed, "Integration of Power-to-Gas in Gasendal and GoBiGas," Publications.Lib.Chalmers.Se, pp. 1-70, 2013.

[61] S. Seyednejadian, R. Rauch, S. Bensaid, H. Hofbauer, G. Weber, and G. Saracco, "Power to Fuels: Dynamic Modeling of a Slurry Bubble Column Reactor in Lab-Scale for Fischer Tropsch Synthesis under Variable Load of Synthesis Gas," Appl. Sci., 2018.

[62] M. Hillestad et al., "Improving carbon efficiency and profitability of the biomass to liquid process with hydrogen from renewable power," Fuel, 2018.

[63] X. Lu, D. Hildebrandt, and D. Glasser, "Distribution between C2 and C3 in Low Temperature FischerTropsch Synthesis over a TiO2-Supported Cobalt Catalyst," Appl. Catal. A Gen., vol. 506, pp. 67-76, 2015.

[64] G. P. Van Der Laan and A. A. C. M. Beenackers, "Kinetics and Selectivity of the Fischer-Tropsch Synthesis: A Literature Review," Catal. Rev. - Sci. Eng., 1999.

[65] G. P. van der Laan, Kinetics, Selectivity and Scale Up of the Fischer-Tropsch Synthesis. 1999.

[66] S. lqbal et al., "Fischer Tropsch Synthesis using promoted cobalt-based catalysts," Catal. Today, vol. 272, pp. 74-79, 2016.

[67] M. van der Riet, R. G. Copperthwaite, and G. J. Hutchings, "Formation of hydrocarbons from $\mathrm{CO}+\mathrm{H} 2$ using a cobalt-manganese oxide catalyst. A 13C isotopic study," J. Chem. Soc. Faraday Trans. 1 Phys. Chem. Condens. Phases, vol. 83, no. 9, p. 2963, 1987.

[68] A. C. Gujar, V. K. Guda, M. Nolan, Q. Yan, H. Toghiani, and M. G. White, "Reactions of methanol and higher alcohols over H-ZSM-5," Appl. Catal. A Gen., 2009.

[69] Q. Zhang, X. Li, K. Asami, S. Asaoka, and K. Fujimoto, "Synthesis of LPG from synthesis gas," in Fuel Processing Technology, 2004.

[70] Q. Zhang, T. Ma, M. Zhao, T. Tomonobu, and X. Li, "Direct synthesis of LPG from syngas in a slurry phase," Catal. Sci. Technol., 2016.

[71] Q. Zhang, X. Li, K. Asami, S. Asaoka, and K. Fujimoto, "A highly stable and efficient catalyst for direct 
synthesis of LPG from syngas," Catal. Letters, 2005.

[72] R. A. Dagle et al., "Syngas conversion to gasoline-range hydrocarbons over $\mathrm{Pd} / \mathrm{ZnO} / \mathrm{Al} 2 \mathrm{O} 3 \mathrm{and} \mathrm{ZSM}-5$ composite catalyst system," Fuel Process. Technol., 2014.

[73] P. S. E. A. Quadrelli, K. Armstrong, "Chapter 16 - Potential CO2 Utilisation Contributions to a More Carbon-Sober Future: A 2050 Vision," in Carbon Dioxide Utilisation, 2015, pp. 285-302.

[74] S. Rönsch et al., "Review on methanation - From fundamentals to current projects," Fuel, vol. 166. pp. 276-296, 2016.

[75] J. Schneider et al., "Performance of supported and unsupported Fe and Co catalysts for the direct synthesis of light alkenes from synthesis gas," Fuel Process. Technol., 2018.

[76] H. Schulz, "Selforganization in Fischer-Tropsch synthesis with iron- and cobalt catalysts," in Catalysis Today, 2014.

[77] Y. Yao, X. Liu, D. Hildebrandt, and D. Glasser, "Fischer-Tropsch synthesis using H 2/CO/CO 2 syngas mixtures over an iron catalyst," Ind. Eng. Chem. Res., 2011.

[78] X. Ma, Q. Ge, J. Ma, and H. Xu, "Synthesis of LPG via DME from syngas in two-stage reaction system," Fuel Process. Technol., 2013.

[79] S. Ilias and A. Bhan, "Mechanism of the catalytic conversion of methanol to hydrocarbons," ACS Catalysis. 2013.

[80] N. E. Tsakoumis, M. Rønning, Ø. Borg, E. Rytter, and A. Holmen, "Deactivation of cobalt based FischerTropsch catalysts: A review," in Catalysis Today, 2010.

[81] S. M. Kim, J. W. Bae, Y. J. Lee, and K. W. Jun, "Effect of CO2in the feed stream on the deactivation of Co/Y-Al2O3Fischer-Tropsch catalyst," Catal. Commun., 2008.

[82] O. O. James, A. M. Mesubi, T. C. Ako, and S. Maity, "Increasing carbon utilization in Fischer-Tropsch synthesis using H2-deficient or CO2-rich syngas feeds," Fuel Processing Technology. 2010.

[83] D. Tristantini, S. Lögdberg, B. Gevert, $\varnothing$. Borg, and A. Holmen, "The effect of synthesis gas composition on the Fischer-Tropsch synthesis over $\mathrm{Co} / \mathrm{y}-\mathrm{Al} 2 \mathrm{O} 3$ and $\mathrm{Co}-\mathrm{Re} / \mathrm{y}-\mathrm{Al} 2 \mathrm{O} 3$ catalysts," Fuel Process. Technol., 2007.

[84] C. M. van der Meijden, H. J. Veringa, and L. P. L. M. Rabou, "The production of synthetic natural gas (SNG): A comparison of three wood gasification systems for energy balance and overall efficiency," Biomass and Bioenergy, vol. 34, no. 3, pp. 302-311, 2010.

[85] S. Mesfun, J. Lundgren, A. Toffolo, G. Lindbergh, C. Lagergren, and K. Engvall, "Integration of an Electrolysis Unit for Producer Gas Conditioning in a Bio-Synthetic Natural Gas Plant," J. Energy Resour. Technol., 2018.

[86] H. Thunman et al., "Advanced biofuel production via gasification - lessons learned from 200 man-years of research activity with Chalmers' research gasifier and the GoBiGas demonstration plant," Energy Sci. Eng., 2018.

[87] C. Tagliaferri, S. Evangelisti, R. Clift, P. Lettieri, C. Chapman, and R. Taylor, "Life cycle assessment of conventional and advanced two-stage energy-from-waste technologies for methane production," $J$. Clean. Prod., 2016.

[88] I. Hannula, "Hydrogen enhancement potential of synthetic biofuels manufacture in the European context: A techno-economic assessment," Energy, 2016. 